\title{
MOLECULAR DETECTION OF SALMONELLA AND E. COLI MICROORGANISMS AMONG DAIRY FARMS WITH DETECTION OF VIRULENCE AND ANTIBIOTICS RESISTANCE GENES
}

\author{
GIHAN MOHAMED OMER MOHAMED HASSAN ${ }^{1}$ \\ and HASSAN EL-SAYED MOHAMED FARAG ${ }^{2}$ \\ ${ }^{1}$ Assistance Researcher of Microbiology Department, Port-Said Lab Animal Health Research Institute Dokki -Giza. \\ ${ }^{2}$ Chief Researcher of Food Hygiene Department, Port-Said Lab Animal Health Research Institute Dokki -Giza.
}

Received: 31 March 2019; Accepted: 30 April 2019

\begin{abstract}
A total of 500 samples, 100 of each milk, feed, swabs from milking equipment (milk tanks), drinking tanks swabs and dairy cows fecal swabs samples were collected from different small herds of apparently or subclinical dairy cattle in El-Kabotti and Bahr El-Baker zone at Port-Said Governorates during the period from September to December 2018. The samples were examined for isolation and identification of Salmonella species and E. coli with studied of their virulence and resistance gens and sequence of some genes. The results revealed that Salmonella species and E. coli could be detected in a percentage of $1.8 \%$ and $2.8 \%$ respectively from the examined samples. Salmonella isolates from the examined samples were identified biochemically and serological as $S$. Typhimurium $S$. Entiriditis and $S$. saintipaul with a percentage of $66.67 \%(6 / 9), 2.22 \%(2 / 9)$ and $11.11 \%$ (1/9) respectively, while that of $E$. coli were O26 (5/14), O119 (2/14), O125 (4/14), O126 (1/14) and $\mathrm{O} 127(2 / 14)$ with a percentage of $35.71 \%, 14.28 \%, 28.60 \%, 7.14 \%$ and $14.28 \%$ respectively. The isolated strains of Salmonella species $(\mathrm{n}=9)$ and E. coli stains $(\mathrm{N}=14)$ were investigated for antibiotic susceptibility profile to 10 antibacterial agents by disc diffusion method. The resistances of the isolated Salmonella and E. coli strains were ranged from a various degree of resistances to complete resistances (100\%). By using conventional PCR, all Salmonella were harbored InvA, stn and bcfC genes while E. coli were harbored PhoA, TraT and fimH genes. The resistance genes that detected in Salmonella strains were ampC, $m p h A$ and aacC while that of E. coli were bltEm, ampC, mphA, Aadal and aacC. The prevalence of the resistance genes were discussed. DNA sequencing of sth and bcfC genes for Salmonella and TraT and fimH genes for E. coli were discussed and compared with other strains in Gen Bank. The mutations in quinolone-resistance gene were studied by determining regions of the gyrA gene for Salmonella and E. coli. The public health hazards of these microorganisms as well as recommended measures to improve hygiene measures in dairy farms were discussed.
\end{abstract}

Key words: Salmonella species, E. coli, milk, fecal, swabs of milking equipment's, swabs of drinking equipment, feed, PCR, virulence genes, resistance genes, sequence of genes, public health.

\section{INTRODUCTION}

Although there have been increases in the modern and advanced methods of care for livestock, small herds in different localities were still found especially in the developing and underdeveloped country whereas the growth of animals in conditions of overcrowding often enhanced the appearance of bacterial and others infectious disease (Godinho and Carvalho, 2013) that affect the animals health and their productivity, resulting in large economic losses. Bacteria can occur in milk through, colonization in the teat canal or infected udder (clinical and subclinical mastitis), milker (manual as

Corresponding author: Dr. Gihan Mohamed Omer Mohamed E-mail address: dr.gehanomer@yahoo.com

Present address: Assistance Researcher of Microbiology Department, Port-Said Lab Animal Health Research Institute Dokki -Giza. well as automated), extraneous dirt, milk utensils and unclean processing water (Hayes et al., 2001). Salmonellae and E. coli are the most economically important pathogens (Achá et al., 2004) affecting dairy cattle and calf.

Salmonella is an enteric pathogen found in the intestinal tract of animals and excreted in feces and spread in water, soil, plant surface, animal feces and dairy farms (Halimi et al., 2014). The severity of infection and symptoms varies depending on the host species and serovars and ranging from severe disease to asymptomatic (Coburn et al., 2007). Although cattle are considered a major reservoir for infections with S. Typhimurium (Nastasi et al., 1993) where Salmonella have been isolated from the feces of healthy cattle and considered a normal or transient member of the gastrointestinal microbial population (Callaway et al., 2005). Salmonellosis manifestations 
include fever, anorexia, diarrhea, dehydration, abortion, decreased milk production, depressed mentation, pneumonia, septic arthritis, meningitis, gangrene of distal extremities and sudden death (Mohler and House, 2009).

Salmonella produce a variety of putative virulence determinants including haemaglutinins, adhesion, invasions, fimbriae exotoxin and endotoxins (Lee et al., 1996). The invA gene of Salmonella contains sequence unique and recognized as an international standard for detection of Salmonella genus (Malorny et al., 2003) and considered a potential diagnostic for all known serovars of Salmonella (Jamshidi et al., 2008). While Salmonella enterotoxin (stn) is a putative virulence factor responsible for enterotoxic activity (Chopra et al., 1999) and $b c f C$ coding for bacterial fimbriae, involved in surface adhesion and gut colonization (Barrow et al., 2010).

On the other hand, E. coli are a large and diverse group of bacteria of the family Enterobacteriaceae commonly found in the lower intestine of a variety of warm-blooded animals including cattle and humans (CDC, 2011).

E. coli is an ideal indicator organism for fecal contamination in water (well water, river water, other contaminated surface waters, soil and plants) or in food (milk, meat, vegetables ect.) (Kaper et al., 2004) and this increase the possibility for presence of enteropathogenic or toxigenic E. coli (Pamela et al., 2008).

The pathogenicity of $E$. coli is dependent on the regulation and interaction between a number of virulence factors, and it is affected by environmental conditions such as host species, host health status, interaction with other bacteria species (Clermont et al., 2011).

E. coli pathovars, such as enteropathogenic E. coli (EPEC), Shiga-toxigenic E. coli (STEC), and enterohemorrhagic E. coli (EHEC), have been observed in dairy herds (Farrokh et al., 2013), milk (Van Kessel et al., 2011) and other dairy products (Solomakos et al., 2009), with a unique set of virulence and colonization factors encoded in the chromosome or in episomal structures (Rúgeles et al., 2010).

Enteropathogenic E. coli (EPEC) strains belonged to a series of $\mathrm{O}$ antigenic groups including 12 serogroups such as O26, O55, O86, O111, O114, O119, O125, O126, O127, O128, O142, and O158 (Hernandes et al., 2009).

Conformation of $E$. coli from other bacteria can detect by the housekeeping gene, phoA (The alkaline phosphastase gene) which present in all E. coli strains (Kong et al., 1995) and encodes for a hydrolase enzyme, responsible for removing phosphate groups from molecule (Chang et al., 1986).

TraT gene is one of the virulent factors of E. coli that have been shown to be located on conjugative plasmids. The TraT (conjugal transfer surface exclusive protein) gene is a major outer membrane protein (Moll et al., 1980) which reduces the susceptibility of bacteria to phagocytosis (Agüero et al., 1984).

FimH is a mannose-specific adhesion located on the tip of type 1 fimbriae of $E$. coli that is responsible for mediating shear-enhanced bacterial adhesion and invasive properties of $E$. coli (Chassaing et al., 2011).

Antimicrobial resisitance has emerged in the past few years as a major problem in human and vetrinary medicine (Lanz et al., 2003) due to the wide spread use and misuse of antimicrobials in farms animals (Suojala et al., 2011). Also uses of antibiotic as growth promotion give raise to antimicrobial resistance in farms animals (Philips et al., 2004). The resistance can occur between and within bacteria through mutation of genes and horizontal gene transfer (Buller et al., 2014). Thus antimicribial resistance strains can increase the treatment cost and period of treatment (Sawant et al., 2007). Therefore, identification of resistance genes of bacteria seems to be so essential in reduction of treatment costs (Suojala et al., 2011).

GyrA (A subunit) is essential for epithelial invasion (Galan and Curtis, 1989), found predominantly in bacteria and composed of a single polypeptide, as in most eukaryotes. GyrA has two functional domains: $\mathrm{N}$-terminal responsible for the breaking- and rejoining function and C-terminal that can bind DNA non-specifically (Huang, 1996).

Thus the aim of the current study was carried out for molecular detection of Salmonella and E. coli in different types of samples in dairy farms with detection of some virulence and resistance genes of the isolated strain. Also genes sequences of some strains were determined.

\section{MATERIALS AND METHODS}

\section{1-Sample collection:}

A total of 500 samples, 100 of each milk (pooling from 1000 lactating cows), feed, swabs from milk tanks, drinking tanks swabs and dairy cows fecal swabs samples (pooling from 1000 lactating cows) were collected from small herds of apparently healthy or subclinical dairy cattle in El-Kabotti and Bahr El-Baker zone at Port-Said Governorates during the period from September to December 2018. Each positive pooling samples were reexamined one by one. 
2-Samples preparation, homogenation and preenrichment:

2-1: Milk samples:

Preparation of teats and udder for milk collection was done according to Cabral et al., 2015. Each milk sample was collected aseptically in clean, sterilized, marked and identified sterilized bottle and Keep in the refrigerator or on ice at $4^{\circ} \mathrm{C}$ until microbiological examination. Under aseptic condition homogenation of milk samples with sterile buffered peptone water $(\mathrm{BPW})$ and incubated at $34^{\circ} \mathrm{C}-38^{\circ} \mathrm{C}$ for $18 \mathrm{~h} \pm 3 \mathrm{~h}$ according to ISO 6887-1:2017 and ISO 68875:2017.

\section{2-2: Feed samples:}

Aseptically collection of feed samples and kept in refrigerator until bacteriological examination. Homogenation of grinding feed with sterile BPW and incubation was done according to ISO 6887 1:2017 and ISO 6887-4:2017.

2-3: Swabs from milking equipment (milk tanks): According to WHO/FAO, 1994 milk tanks swabs were taken under aseptic condition and kept at $4^{\circ} \mathrm{C}$ until bacteriological examination. Preparation of $1: 10$ and incubation at $34^{\circ} \mathrm{C}-38^{\circ} \mathrm{C}$ for $18 \mathrm{~h} \pm 3 \mathrm{~h}$ was done according to ISO 6887-1:(2017).

\section{2-4: Drinking tanks swabs:}

Under aseptic condition drinking tanks swabs were collected and kept at $4^{\circ} \mathrm{C}$ until bacteriological examination according to WHO/FAO, 1994. Preparation of $1: 10$, homogenation and incubation at $34^{\circ} \mathrm{C}-38^{\circ} \mathrm{C}$ for $18 \mathrm{~h} \pm 3 \mathrm{~h}$ (ISO 6887-1:2017).

\section{2-5: Dairy cows fecal swabs:}

Fecal swabs were collected and kept at $4^{\circ} \mathrm{C}$ until bacteriological examination according to WHO/FAO, (1994). Prepare a 1:10 dilution, homogenate and incubation at $34^{\circ} \mathrm{C}-38^{\circ} \mathrm{C}$ for $18 \mathrm{~h} \pm$ 3 h (ISO 6887-1:2017.

\section{3- Isolation of microorganisms:}

\section{3-1: Isolation Salmonella species:}

From each culture, $0.1 \mathrm{ml}$ of pre-enrichment broth was added to $10 \mathrm{ml}$ Rappaport-Vassiliadis broth with soya then incubated at $41.5^{\circ} \mathrm{C} \pm 1{ }^{\circ} \mathrm{C}$ for $24 \mathrm{hr}$ $\pm 3 \mathrm{~h}$. and $1 \mathrm{ml}$ from the culture of the same sample was added to $10 \mathrm{ml}$ Muller-Kauffmann Tetrathionate/ novobiocin broth and incubated at $37^{\circ}$ $\mathrm{C} \pm 1{ }^{\circ} \mathrm{C}$ for $24 \mathrm{hr} \pm 3 \mathrm{~h}$. Then a loopful from the enriched broth was streaked onto the each surface of Xylose Lysine Deoxycholate agar plates and Brilliant Green agar plates then incubated at $37^{\circ} \mathrm{C} \pm 1^{\circ} \mathrm{C}$ for $24 \mathrm{~h} \pm 3 \mathrm{~h}$ according to ISO 6887 $1:(2017)$.

\section{3-2: Isolation $E$. coli:}

A loopful of the homogenate (pre-enriched culture were added to Lauryl sulphate tryptose broth (LST) test tube and incubated at $35^{\circ} \mathrm{C} \pm 0.5^{\circ} \mathrm{C}$. A loopful of each positive cultured tube (turbid and gas production) was transferred to tube of $E$. coli medium, (EC) and incubated at $44.5^{\circ} \mathrm{C}$ for $48 \pm 3 \mathrm{~h}$ examined each $24 \pm 2 \mathrm{~h}$ for gas production. A loopful from positive culture of EC broth was streak on L-EMB agar plate and incubates for $18-24 \mathrm{~h}$ at $35^{\circ} \mathrm{C} \pm 0.5^{\circ} \mathrm{C}$ according to FDA's, (2017).

\section{4- Identification of microorganisms:}

\section{4-1: Biochemical identification:}

4-1-1: Biochemical identification of Salmonella species:

Presumptive colony with a characteristic morphology of typical Salmonella species were subjected to biochemical identification according to ISO 6579-1: (2017).

\section{4-1-2: Biochemical identification of $\boldsymbol{E}$. coli:}

The suspected typical colonies of E. coli on L-EMB media was conducted to Gram's staining, oxidase and catalase tests. Then the colonies were subjected to various biochemical tests (Hitchins et al., 2001).

\section{4-2: Serological identification of the isolates:}

All biochemically identified Salmonella species and $E$. coli isolates were subjected to serologically identification.

\section{4-2-1: Serological identification of Salmonella isolates:}

Pure and primary culture plate of Salmonella species isolates were serotyped by slide agglutination test depending upon white-KauffmanLe Minor scheme according to Grimont and Weill, 2007.

\section{4-2-2: Serological identification of $E$. coli isolates:}

Pure and primary culture plate of E. coli was agglutinated by slide agglutination test based on the presence of three principal surface antigens, Oantigens, flagellar $\mathrm{H}$-antigens, and capsular $\mathrm{K}$ antigens according to Ørskov and Ørskov (1984).

\section{5-Antibiotic susceptibility testing:}

All confirmed Salmonella serovars and E. coli serotypes were conducted to the antimicrobial susceptibility testing using the agar disk diffusion method and the interpretation of the results according to CLSI, (2013). All isolates were tested for susceptibility to 10 different antimicrobials agents as follows: ceftroiaxon (CRO) $30 \mu \mathrm{g}$; erythromycin (E) $15 \mu \mathrm{g}$; gentamicin $(\mathrm{CN}) 10 \mu \mathrm{g}$; lioncomycin (MY) $10 \mu \mathrm{g}$; oxolinic acid (OA) $2 \mu \mathrm{g}$; oxytetracycline (OT) 30 $\mu$; penicillin G (P) 10 I.U; streptomycin (S) $10 \mu \mathrm{g} ; \quad$ trimethoprim + sulphamethoxazole $(\mathrm{SXT})(1.25+23.75) \mu \mathrm{g}$ and vancomycin (VA) $30 \mu \mathrm{g}$. 


\section{6-Molecular study:}

6-1: Conformation of Salmonella spp. and $E$. coli and their virulence and antibiotics resistance genes:

\section{6-1-1: DNA extraction:}

DNA extraction from samples was performed using the QIAamp DNA Mini kit (Qiagen, Germany, $\mathrm{GmbH}$ ) with modifications from the manufacturer's recommendations. Briefly, $200 \mu \mathrm{l}$ of the sample suspension was incubated with $10 \mu \mathrm{l}$ of proteinase $\mathrm{K}$ and $200 \mu \mathrm{l}$ of lysis buffer at $56^{\circ} \mathrm{C}$ for $10 \mathrm{~min}$. After incubation, $200 \mu 1$ of $100 \%$ ethanol was added to the lysate. The sample was then washed and centrifuged following the manufacturer's recommendations. Nucleic acid was eluted with $100 \mu \mathrm{l}$ of elution buffer.

\section{6-1-2: Oligonucleotide Primer:}

Primers used were supplied from Metabion (Germany) are listed in table (1).

Table 1: Primers sequences, target genes, amplicon sizes and cycling conditions.

\begin{tabular}{|c|c|c|c|c|c|c|c|c|}
\hline \multirow[t]{2}{*}{ Target gene } & \multirow[t]{2}{*}{ Primers sequences } & \multirow{2}{*}{$\begin{array}{l}\text { Amplified } \\
\text { segment } \\
\text { (bp) }\end{array}$} & \multirow{2}{*}{$\begin{array}{c}\text { Primary } \\
\text { denaturation }\end{array}$} & \multicolumn{5}{|c|}{ Amplification (35 cycles) } \\
\hline & & & & $\begin{array}{c}\text { Secondary } \\
\text { denaturation }\end{array}$ & Annealing & Extension & $\begin{array}{c}\text { Final } \\
\text { extension }\end{array}$ & Reference \\
\hline $\begin{array}{l}\text { E. coli } \\
\text { phoA }\end{array}$ & $\begin{array}{l}\text { CGATTCTGGAAAT } \\
\text { GGCAAAAG } \\
\text { CGTGATCAGCGGT } \\
\text { GACTATGAC }\end{array}$ & 720 & $\begin{array}{l}94^{\circ} \mathrm{C} \\
5 \mathrm{~min} .\end{array}$ & $\begin{array}{c}94^{\circ} \mathrm{C} \\
30 \mathrm{sec} .\end{array}$ & $\begin{array}{c}55^{\circ} \mathrm{C} \\
40 \mathrm{sec} .\end{array}$ & $\begin{array}{c}72^{\circ} \mathrm{C} \\
45 \mathrm{sec} .\end{array}$ & $\begin{array}{c}72^{\circ} \mathrm{C} \\
10 \mathrm{~min} .\end{array}$ & $\begin{array}{c}\text { Hu et al., } \\
\text { (2011) }\end{array}$ \\
\hline $\begin{array}{l}\text { Salmonella } \\
\text { invA }\end{array}$ & $\begin{array}{l}\text { GTGAAATTATCGC } \\
\text { CACGTTCGGGCAA } \\
\text { TCATCGCACCGTC } \\
\text { AAAGGAACC }\end{array}$ & 284 & $\begin{array}{l}94^{\circ} \mathrm{C} \\
5 \mathrm{~min} .\end{array}$ & $\begin{array}{l}94^{\circ} \mathrm{C} \\
30 \mathrm{sec} .\end{array}$ & $\begin{array}{c}55^{\circ} \mathrm{C} \\
30 \mathrm{sec} .\end{array}$ & $\begin{array}{c}72^{\circ} \mathrm{C} \\
30 \mathrm{sec} .\end{array}$ & $\begin{array}{l}72^{\circ} \mathrm{C} \\
7 \mathrm{~min} .\end{array}$ & $\begin{array}{l}\text { Oliveira } \\
\text { et al., } \\
(\mathbf{2 0 0 3 )}\end{array}$ \\
\hline blaTEM & $\begin{array}{l}\text { ATCAGCAATAAAC } \\
\text { CAGC } \\
\text { CCCCGAAGAACGT } \\
\text { TTTC }\end{array}$ & 516 & $\begin{array}{c}94^{\circ} \mathrm{C} \\
5 \mathrm{~min} .\end{array}$ & $\begin{array}{l}94^{\circ} \mathrm{C} \\
30 \mathrm{sec} .\end{array}$ & $\begin{array}{c}54^{\circ} \mathrm{C} \\
40 \mathrm{sec} .\end{array}$ & $\begin{array}{l}72^{\circ} \mathrm{C} \\
45 \mathrm{sec} .\end{array}$ & $\begin{array}{c}72^{\circ} \mathrm{C} \\
10 \mathrm{~min} .\end{array}$ & $\begin{array}{l}\text { Colom } \\
\text { et al., } \\
(\mathbf{2 0 0 3})\end{array}$ \\
\hline Aadal & $\begin{array}{c}\text { TATCAGAGGTAGT } \\
\text { TGGCGTCAT } \\
\text { GTTCCATAGCGTT } \\
\text { AAGGTTTCATT }\end{array}$ & 484 & $\begin{array}{l}94^{\circ} \mathrm{C} \\
5 \mathrm{~min} .\end{array}$ & $\begin{array}{c}94^{\circ} \mathrm{C} \\
30 \mathrm{sec} .\end{array}$ & $\begin{array}{c}54^{\circ} \mathrm{C} \\
40 \mathrm{sec}\end{array}$ & $\begin{array}{c}72^{\circ} \mathrm{C} \\
45 \mathrm{sec}\end{array}$ & $\begin{array}{c}72^{\circ} \mathrm{C} \\
10 \mathrm{~min} .\end{array}$ & $\begin{array}{l}\text { Randall } \\
\text { et al., } \\
(2004)\end{array}$ \\
\hline$a m p C$ & $\begin{array}{c}\text { TTCTATCAAMACT } \\
\text { GGCARCC } \\
\text { CCYTTTTATGTAC } \\
\text { CCAYGA }\end{array}$ & 550 & $\begin{array}{l}94^{\circ} \mathrm{C} \\
5 \mathrm{~min} .\end{array}$ & $\begin{array}{l}94^{\circ} \mathrm{C} \\
30 \mathrm{sec} .\end{array}$ & $\begin{array}{c}60^{\circ} \mathrm{C} \\
40 \mathrm{sec} .\end{array}$ & $\begin{array}{c}72^{\circ} \mathrm{C} \\
45 \mathrm{sec} .\end{array}$ & $\begin{array}{c}72^{\circ} \mathrm{C} \\
10 \mathrm{~min} .\end{array}$ & $\begin{array}{l}\text { Lynne } \\
\text { et al., } \\
(\mathbf{2 0 0 8})\end{array}$ \\
\hline$\overline{a a c C}$ & $\begin{array}{c}\text { GGCGCGATCAAC } \\
\text { GAATTTATCCGA } \\
\text { CCATTCGATGCCG } \\
\text { AAGGAAACGAT }\end{array}$ & 48 & $\begin{array}{l}94^{\circ} \mathrm{C} \\
5 \mathrm{~min} .\end{array}$ & $\begin{array}{l}94^{\circ} \mathrm{C} \\
30 \mathrm{sec} .\end{array}$ & $\begin{array}{c}60^{\circ} \mathrm{C} \\
40 \mathrm{sec} .\end{array}$ & $\begin{array}{c}72^{\circ} \mathrm{C} \\
45 \mathrm{sec} .\end{array}$ & $\begin{array}{c}72^{\circ} \mathrm{C} \\
10 \mathrm{~min} .\end{array}$ & $\begin{array}{l}\text { Lynne } \\
\text { et al., } \\
(\mathbf{2 0 0 8})\end{array}$ \\
\hline fimH & $\begin{array}{c}\text { TGCAGAACGGAT } \\
\text { AAGCCGTGG } \\
\text { GCAGTCACCTGCC } \\
\text { CTCCGGTA }\end{array}$ & 508 & $\begin{array}{l}94^{\circ} \mathrm{C} \\
5 \mathrm{~min} .\end{array}$ & $\begin{array}{l}94^{\circ} \mathrm{C} \\
30 \mathrm{sec} .\end{array}$ & $\begin{array}{c}50^{\circ} \mathrm{C} \\
40 \mathrm{sec} .\end{array}$ & $\begin{array}{c}72^{\circ} \mathrm{C} \\
45 \mathrm{sec} .\end{array}$ & $\begin{array}{c}72^{\circ} \mathrm{C} \\
10 \mathrm{~min} .\end{array}$ & $\begin{array}{l}\text { Ghanbar } \\
\text { pour and } \\
\text { Salehi, } \\
(2010)\end{array}$ \\
\hline$\overline{T r a T}$ & $\begin{array}{c}\text { GATGGCTGAACCG } \\
\text { TGGTTATG } \\
\text { CACACGGGTCTGG } \\
\text { TATTTATGC }\end{array}$ & 307 & $\begin{array}{l}94^{\circ} \mathrm{C} \\
5 \mathrm{~min} .\end{array}$ & $\begin{array}{l}94^{\circ} \mathrm{C} \\
30 \mathrm{sec} .\end{array}$ & $\begin{array}{c}55^{\circ} \mathrm{C} \\
40 \mathrm{sec}\end{array}$ & $\begin{array}{l}72^{\circ} \mathrm{C} \\
40 \mathrm{sec} .\end{array}$ & $\begin{array}{c}72^{\circ} \mathrm{C} \\
10 \mathrm{~min} .\end{array}$ & $\begin{array}{l}\text { Kaipainen } \\
\text { et al., (2002) }\end{array}$ \\
\hline $\operatorname{stn}$ & $\begin{array}{c}\text { TTG TGT CGC TAT } \\
\text { CAC TGG CAA CC } \\
\text { ATT CGT AAC CCG } \\
\text { CTC TCG TCC }\end{array}$ & 617 & $\begin{array}{l}94^{\circ} \mathrm{C} \\
5 \mathrm{~min} .\end{array}$ & $\begin{array}{l}94^{\circ} \mathrm{C} \\
30 \mathrm{sec} .\end{array}$ & $\begin{array}{l}59^{\circ} \mathrm{C} \\
40 \mathrm{sec} .\end{array}$ & $\begin{array}{l}72^{\circ} \mathrm{C} \\
40 \mathrm{sec}\end{array}$ & $\begin{array}{c}72^{\circ} \mathrm{C} \\
10 \mathrm{~min} .\end{array}$ & $\begin{array}{l}\text { Murugkar } \\
\text { et al., (2003) }\end{array}$ \\
\hline$b c f C$ & $\begin{array}{c}\text { ACC AGA GAC ATT } \\
\text { GCC TTC C } \\
\text { TTC TGC TCG CCG } \\
\text { CTA TTC G }\end{array}$ & 467 & $\begin{array}{l}94^{\circ} \mathrm{C} \\
5 \mathrm{~min} .\end{array}$ & $\begin{array}{l}94^{\circ} \mathrm{C} \\
30 \mathrm{sec} .\end{array}$ & $\begin{array}{c}53^{\circ} \mathrm{C} \\
40 \mathrm{sec} .\end{array}$ & $\begin{array}{l}72^{\circ} \mathrm{C} \\
45 \mathrm{sec}\end{array}$ & $\begin{array}{c}72^{\circ} \mathrm{C} \\
10 \mathrm{~min} .\end{array}$ & $\begin{array}{l}\text { Huehn } \\
\text { et al., } \\
(\mathbf{2 0 1 0})\end{array}$ \\
\hline$m p h A$ & $\begin{array}{c}\text { GTGAGGAGGAGC } \\
\text { TTCGCGAG } \\
\text { TGCCGCAGGACTC } \\
\text { GGAGGTC }\end{array}$ & 403 & $\begin{array}{l}94^{\circ} \mathrm{C} \\
5 \mathrm{~min} .\end{array}$ & $\begin{array}{l}94^{\circ} \mathrm{C} \\
30 \mathrm{sec} .\end{array}$ & $\begin{array}{c}58^{\circ} \mathrm{C} \\
40 \mathrm{sec}\end{array}$ & $\begin{array}{l}72^{\circ} \mathrm{C} \\
45 \mathrm{sec}\end{array}$ & $\begin{array}{c}72^{\circ} \mathrm{C} \\
10 \mathrm{~min} .\end{array}$ & $\begin{array}{l}\text { Nguyen } \\
\text { et al., } \\
(2009)\end{array}$ \\
\hline gyrA & $\begin{array}{c}\text { AAATCTGCCCGTG } \\
\text { TCGTTGGT } \\
\text { GCCATACCTACTG } \\
\text { CGATACC }\end{array}$ & 344 & $\begin{array}{l}94^{\circ} \mathrm{C} \\
5 \mathrm{~min} .\end{array}$ & $\begin{array}{l}94^{\circ} \mathrm{C} \\
30 \mathrm{sec} .\end{array}$ & $\begin{array}{c}58^{\circ} \mathrm{C} \\
40 \mathrm{sec} .\end{array}$ & $\begin{array}{l}72^{\circ} \mathrm{C} \\
40 \mathrm{sec}\end{array}$ & $\begin{array}{c}72^{\circ} \mathrm{C} \\
10 \mathrm{~min} .\end{array}$ & $\begin{array}{l}\text { Fàbrega } \\
\text { et al., } \\
\text { (2009) }\end{array}$ \\
\hline
\end{tabular}




\section{6-1-3: PCR amplification:}

Primers were utilized in $25 \mu \mathrm{l}$ reactions containing $12.5 \mu \mathrm{l}$ of Emerald Amp Max PCR Master Mix (Takara, Japan), $1 \mu$ l of each primer of 20 pmol concentrations, $4.5 \mu \mathrm{l}$ of water, and $6 \mu \mathrm{l}$ of DNA template. The reaction was performed in an applied biosystem 2720 thermal cycler.

\section{6-1-4: Analysis of the PCR Products:}

The products of PCR were separated by electrophoresis on 1.5\% agarose gel (Applichem, Germany, $\mathrm{GmbH}$ ) in $1 \mathrm{x}$ TBE buffer at room temperature using gradients of $5 \mathrm{~V} / \mathrm{cm}$. For gel analysis, $20 \mu \mathrm{l}$ of the products was loaded in each gel slot. Gelpilot 100 bp (Qiagen, Germany, GmbH) and gene ruler 100 bp ladder (Fermentas, Germany) were used to determine the fragment sizes. The gel was photographed by a gel documentation system (Alpha Innotech, Biometra) and the data was analyzed through computer software.

\section{6-1-5: DNA Sequence:}

PCR products were purified using QIAquick PCR Product extraction kit. (Qiagen, Valencia). Big dye Terminator V3.1 cycle sequencing kit (PerkinElmer) was used for the sequence reaction and then it was purified using Centrisep spin column. DNA sequences were obtained by Applied Biosystems 3130 genetic analyzer (HITACHI, Japan), A BLAST ${ }^{\circledR}$ analysis (Basic Local Alignment Search Tool) (Altschul et al., 1990) was initially performed to establish sequence identity to Gene Bank accessions.

\section{6-1-6: Phylogenetic analysis:}

The phylogenetic tree was created by the Meg Align module of Laser gene DNA Star (Thompson et al., 1994) and Phylogenetic analyses was done using maximum likelihood, neighbor joining and maximum parsimony in MEGA6 (Tamura et al., 2013).

\section{RESULTS}

Table 2: Prevalence of the isolated Salmonella species and E. coli isolated from the examined samples.

\begin{tabular}{lccccc}
\hline \multirow{2}{*}{ Types of samples } & $\begin{array}{c}\text { Samples } \\
\text { number }\end{array}$ & \multicolumn{2}{c}{$\begin{array}{c}\text { Positive samples for } \\
\text { Salmonella } \text { spp. }\end{array}$} & \multicolumn{2}{c}{$\begin{array}{c}\text { Positive samples for } \\
\text { E. coli }\end{array}$} \\
\cline { 2 - 6 } & No. & No. & $\%$ & No. & $\%$ \\
\hline Milk & 100 & 1 & 1 & 2 & 2 \\
\hline Feed & 100 & 1 & 1 & 2 & 2 \\
\hline $\begin{array}{l}\text { Milking equipment's swabs } \\
\text { (milk tanks) }\end{array}$ & 100 & 1 & 1 & 1 & 1 \\
\hline Drinking tanks Swabs & 100 & 1 & 1 & 1 & 1 \\
\hline Fecal swabs & 100 & 5 & 5 & 8 & 8 \\
\hline Total & 500 & 9 & 1.8 & 14 & 2.8 \\
\hline
\end{tabular}

Table 3: Prevalence of Salmonella serotyping $(n=9)$ isolated from the examined samples.

\begin{tabular}{|c|c|c|c|c|c|c|c|c|c|c|c|}
\hline \multirow{3}{*}{$\begin{array}{l}\text { Salmonella } \\
\text { species }\end{array}$} & \multirow{3}{*}{ 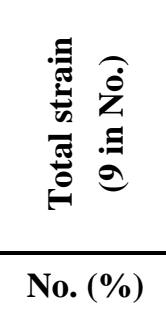 } & \multicolumn{10}{|c|}{ Examined samples } \\
\hline & & \multicolumn{2}{|c|}{ Milk } & \multicolumn{2}{|c|}{ Feed } & \multicolumn{2}{|c|}{$\begin{array}{l}\text { Milking } \\
\text { equipment's } \\
\text { swabs } \\
\text { (milk tanks) }\end{array}$} & \multicolumn{2}{|c|}{$\begin{array}{c}\text { Drinking } \\
\text { tanks } \\
\text { swabs }\end{array}$} & \multicolumn{2}{|c|}{$\begin{array}{l}\text { Fecal } \\
\text { swabs }\end{array}$} \\
\hline & & No. & $\%$ & No. & $\%$ & No. & $\%$ & No. & $\%$ & No. & $\%$ \\
\hline $\begin{array}{l}S . \text { Typhimurium } \\
\underline{1}, 4,[5], 12: 1: 1,2\end{array}$ & $6 / 9(66.67)$ & $1 / 6$ & 16.67 & $1 / 6$ & 16.67 & $1 / 6$ & 16.67 & $\mathbf{0}$ & $\mathbf{0}$ & $3 / 6$ & 50 \\
\hline $\begin{array}{l}\text { S. Enteritidis } \\
1,9,12: \mathrm{g}, \mathrm{m} \text { :- }\end{array}$ & $2 / 9(22.22)$ & $\mathbf{0}$ & $\mathbf{0}$ & $\mathbf{0}$ & $\mathbf{0}$ & $\mathbf{0}$ & $\mathbf{0}$ & $1 / 2$ & 50 & $1 / 2$ & 50 \\
\hline $\begin{array}{l}\text { S. Saintipaul } \\
\underline{1}, 4,[5], 12: e, h: 1,2\end{array}$ & 1/9 (11.11) & $\mathbf{0}$ & $\mathbf{0}$ & $\mathbf{0}$ & $\mathbf{0}$ & $\mathbf{0}$ & $\mathbf{0}$ & $\mathbf{0}$ & $\mathbf{0}$ & $1 / \mathbf{1}$ & 100 \\
\hline
\end{tabular}


Table 4: Prevalence of $E$. coli serotyping $(\mathrm{n}=14)$ isolated from the examined samples.

\begin{tabular}{|c|c|c|c|c|c|c|c|c|c|c|c|}
\hline \multirow{3}{*}{ E. coli } & \multirow{3}{*}{ 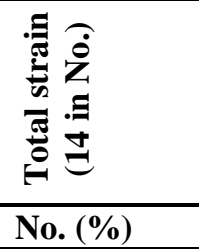 } & \multicolumn{10}{|c|}{ Examined samples } \\
\hline & & \multicolumn{2}{|c|}{ Milk } & \multicolumn{2}{|c|}{ Feed } & \multicolumn{2}{|c|}{$\begin{array}{c}\text { Milking } \\
\text { equipment's } \\
\text { swabs } \\
\text { (milk tanks) } \\
\end{array}$} & \multicolumn{2}{|c|}{$\begin{array}{c}\text { Drinking tanks } \\
\text { swabs }\end{array}$} & Fecal & \multirow[t]{2}{*}{ swabs } \\
\hline & & No. & $\%$ & No. & $\%$ & No. & $\%$ & No. & $\%$ & No. & \\
\hline $\mathbf{0 2 6}$ & $5 / 14(35.71)$ & $\mathbf{0}$ & $\mathbf{0}$ & $1 / 5$ & 20.00 & $\mathbf{0}$ & $\mathbf{0}$ & $\mathbf{0}$ & $\mathbf{0}$ & $4 / 5$ & 80.00 \\
\hline 0119 & $2 / 14(14.28)$ & $\mathbf{0}$ & $\mathbf{0}$ & $\mathbf{0}$ & $\mathbf{0}$ & $1 / 2$ & 50 & $\mathbf{0}$ & $\mathbf{0}$ & $1 / 2$ & 50 \\
\hline $\mathbf{O 1 2 5}$ & $4 / 14(28.60)$ & $1 / 4$ & 25.00 & $1 / 4$ & 25.00 & $\mathbf{0}$ & $\mathbf{0}$ & $1 / 4$ & 25.00 & $1 / 4$ & 25.00 \\
\hline 0126 & $1 / 14(7.14)$ & $\mathbf{0}$ & $\mathbf{0}$ & $\mathbf{0}$ & $\mathbf{0}$ & $\mathbf{0}$ & $\mathbf{0}$ & $\mathbf{0}$ & $\mathbf{0}$ & $1 / 1$ & 100 \\
\hline O127 & $2 / 14(14.28)$ & $\mathbf{0}$ & $\mathbf{0}$ & $1 / 2$ & 50 & $\mathbf{0}$ & $\mathbf{0}$ & $\mathbf{0}$ & $\mathbf{0}$ & $1 / 2$ & 50 \\
\hline
\end{tabular}

Table 5: Antimicrobial susceptibility pattern of Salmonella serovar $(n=9)$ and E. coli $(n=14)$ recovered from the examined samples.

\begin{tabular}{|c|c|c|c|c|c|c|c|c|c|c|c|c|c|c|}
\hline \multirow{3}{*}{ Antibiotic agents } & \multirow{3}{*}{ 总 } & \multirow{3}{*}{ 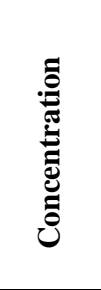 } & \multicolumn{6}{|c|}{ Salmonella isolates $(\mathrm{n}=9)$} & \multicolumn{6}{|c|}{$E$. coli isolates $(n=14)$} \\
\hline & & & \multicolumn{2}{|r|}{ 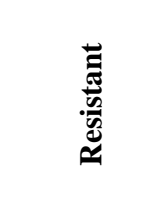 } & \multicolumn{2}{|c|}{ 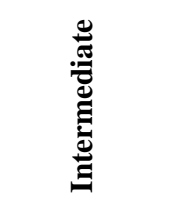 } & \multicolumn{2}{|c|}{ 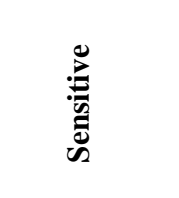 } & \multicolumn{2}{|c|}{ 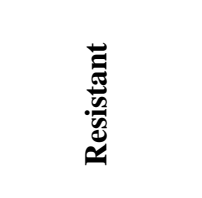 } & \multicolumn{2}{|c|}{ 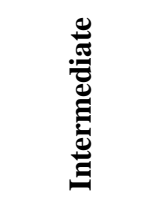 } & \multicolumn{2}{|c|}{ : } \\
\hline & & & No. & $\%$ & No. & $\%$ & No. & $\%$ & No. & $\%$ & No. & $\%$ & No. & $\%$ \\
\hline Ceftroiaxon & CRO & $30 \mu \mathrm{g}$ & 9 & 100 & $\mathbf{0}$ & $\mathbf{0}$ & $\mathbf{0}$ & $\mathbf{0}$ & 14 & 100 & $\mathbf{0}$ & $\mathbf{0}$ & $\mathbf{0}$ & $\mathbf{0}$ \\
\hline Erythromycin & $\mathbf{E}$ & $15 \mu \mathrm{g}$ & 5 & 55.56 & $\mathbf{0}$ & $\mathbf{0}$ & 4 & 44.44 & 3 & 21.42 & 1 & 7.14 & 10 & $\overline{71.42}$ \\
\hline Gentamicin & $\mathbf{C N}$ & $10 \mu \mathrm{g}$ & 9 & 100 & $\mathbf{0}$ & $\mathbf{0}$ & $\mathbf{0}$ & $\mathbf{0}$ & 3 & 21.42 & 3 & 21.42 & 8 & 57.14 \\
\hline Lioncomycin & MY & $10 \mu \mathrm{g}$ & 9 & 100 & $\mathbf{0}$ & $\mathbf{0}$ & $\mathbf{0}$ & $\mathbf{0}$ & 14 & 100 & $\mathbf{0}$ & 0 & $\mathbf{0}$ & 0 \\
\hline Oxolinic acid & $\mathbf{O A}$ & $2 \mu \mathrm{g}$ & 8 & 88.89 & 1 & 11.11 & $\mathbf{0}$ & 0 & 14 & 100 & $\mathbf{0}$ & 0 & 0 & 0 \\
\hline Oxytetracycline & OT & $30 \mu \mathrm{g}$ & 3 & 33.33 & 5 & 55.56 & 1 & 11.11 & 5 & 35.71 & 9 & 64.29 & $\mathbf{0}$ & $\mathbf{0}$ \\
\hline Penicillin G & $\mathbf{P}$ & 10 I.U & 7 & 77.78 & 2 & 22.22 & $\mathbf{0}$ & $\mathbf{0}$ & 14 & 100 & $\mathbf{0}$ & $\mathbf{0}$ & $\mathbf{0}$ & 0 \\
\hline Streptomycin & $\mathbf{S}$ & $10 \mu \mathrm{g}$ & 8 & 88.89 & 1 & 11.11 & $\mathbf{0}$ & $\mathbf{0}$ & 7 & 50.00 & $\mathbf{0}$ & $\mathbf{0}$ & 7 & $\overline{50.00}$ \\
\hline $\begin{array}{l}\text { Trimethoprim + } \\
\text { Sulphamethoxazole }\end{array}$ & SXT & $\begin{array}{c}1.25+ \\
23.75 \\
\mu \mathrm{g}\end{array}$ & 2 & 22.22 & 6 & 66.67 & 1 & 11.11 & 2 & 14.30 & 11 & 78.57 & 1 & 7.14 \\
\hline Vancomycin & VA & $30 \mu \mathrm{g}$ & 9 & 100 & $\mathbf{0}$ & $\mathbf{0}$ & $\mathbf{0}$ & $\mathbf{0}$ & 12 & 85.71 & 2 & 14.30 & $\mathbf{0}$ & $\mathbf{0}$ \\
\hline
\end{tabular}

Table 6: Prevalence of confirmatory genes among Salmonella $(\mathrm{n}=9)$ and E. coli $(\mathrm{n}=14)$ strains isolated from the examined samples

\begin{tabular}{ccc}
\hline & Salmonella serovars $(\mathbf{n}=9)$ & E. coli serovars $(\mathbf{n}=14)$ \\
\hline Confirmatory genes & invA gene & PhoA gene \\
\hline No. of detected genes & $9 / 9$ & $14 / 14$ \\
\hline$\%$ & 100 & 100 \\
\hline
\end{tabular}

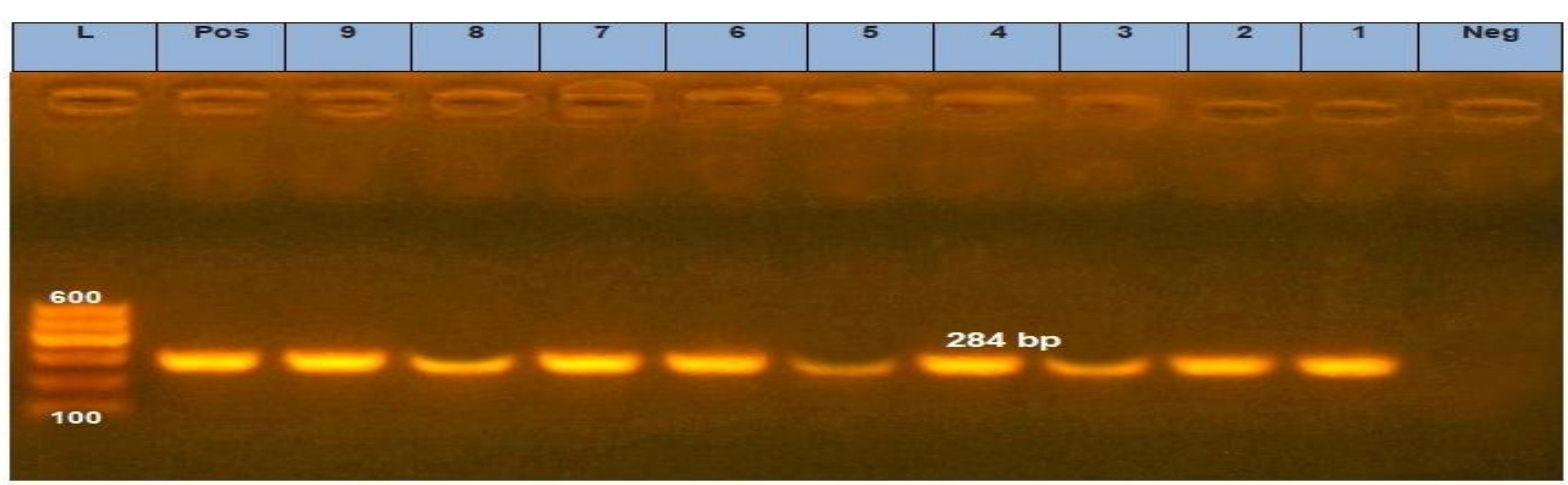

Figure (1): Agarose gel electrophoresis of PCR products after amplification of: 1- invA gene for Salmonella strains, MWM-molecular weight marker (100 - 600 bp DNA ladder), control (Positive, Negative) and different strains of Salmonella species. (invA gene products at $284 \mathrm{bp}$ ). 


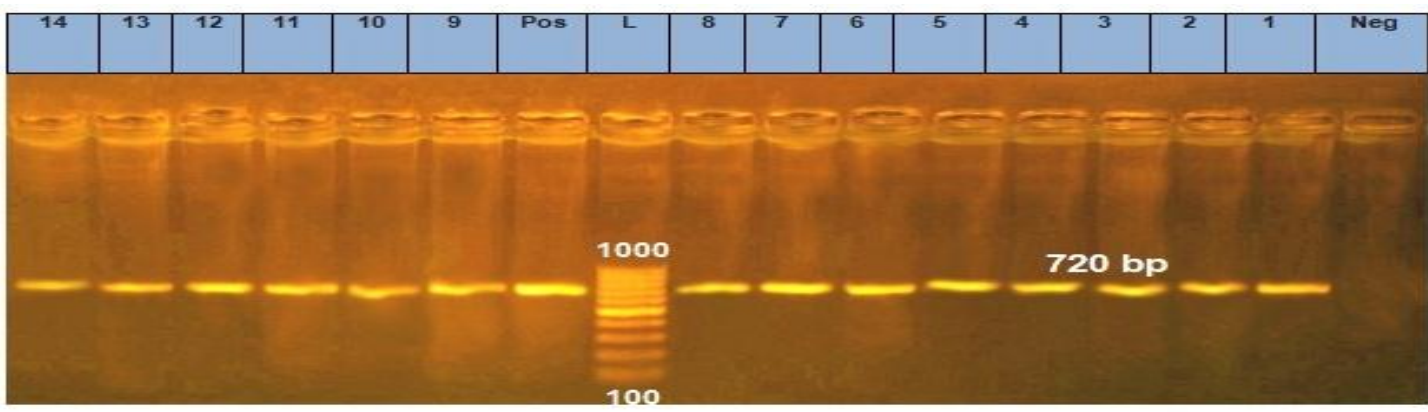

Figure (2): Agarose gel electrophoresis of PCR products after amplification of: 1- phoA gene for E. coli strains, MWM-molecular weight marker (100 - 1000 bp DNA ladder), control (Positive, Negative) and different strains of E. coli. (phoA gene products at $720 \mathrm{bp}$ ).

Table 7: Prevalence of some virulence genes among Salmonella strains $(n=9)$ isolated from the examined samples.

\begin{tabular}{lccccc}
\hline \multirow{2}{*}{ Salmonella strains } & Sample & Total & \multicolumn{3}{c}{ No. of detected genes } \\
\cline { 5 - 6 } & No. & strains & invA & stn & bcfC \\
\hline S. Typhimurium & $2-3-4-5-$ & $6 / 9$ & $6 / 6$ & $6 / 6$ & $6 / 6$ \\
1, 4, [5], 12:i: 1,2 & $6-9$ & $(66.67 \%)$ & $(100 \%)$ & $(100 \%)$ & $(100 \%)$ \\
\hline S. Enteritidis & $7-8$ & $2 / 9$ & $2 / 2$ & $2 / 2$ & $2 / 2$ \\
1, 9, 12: g, m :- & 1 & $1 / 9$ & $1 / 1$ & $1 / 1$ & $(100 \%)$ \\
\hline S. Saintipaul & & $(11.11 \%)$ & $(100 \%)$ & $(100 \%)$ & $(100 \%)$ \\
\hline 1,4,[5],12:e,h: 1,2 & No. & $9 / 9$ & $9 / 9$ & $9 / 9$ & $9 / 9$ \\
Total detected gene & $\%$ & $(100 \%)$ & $(100 \%)$ & $(100 \%)$ & $(100 \%)$ \\
\hline
\end{tabular}

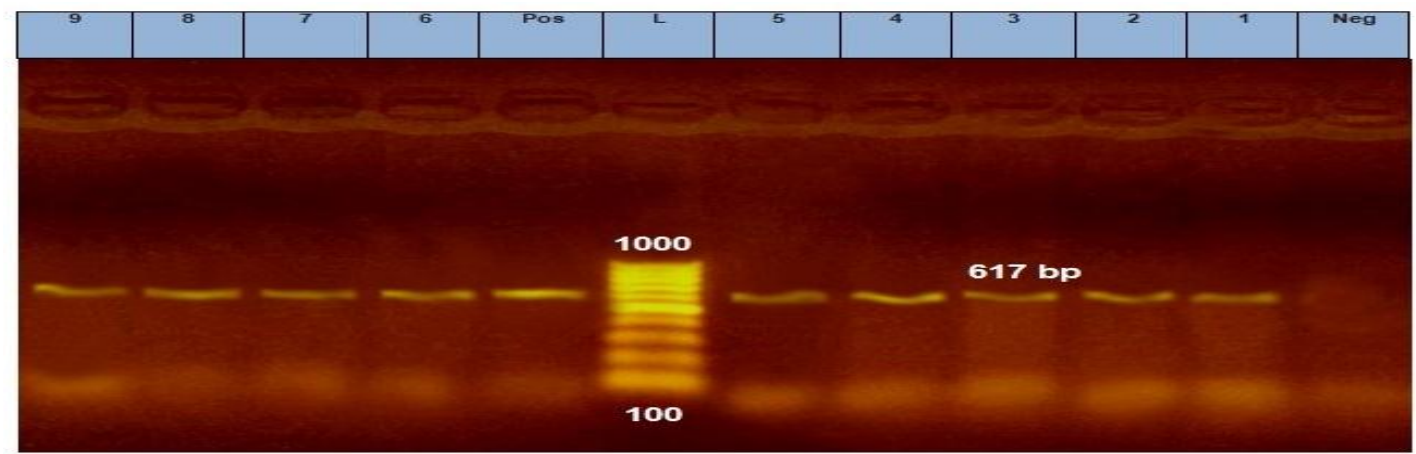

Figure (3): Agarose gel electrophoresis of PCR products after amplification of: 1- stn gene for salmonella strains, MWM-molecular weight marker (100 - 1000 bp DNA ladder), control (Positive, Negative) and different strains of Salmonella (stn gene products at $617 \mathrm{bp}$ ).

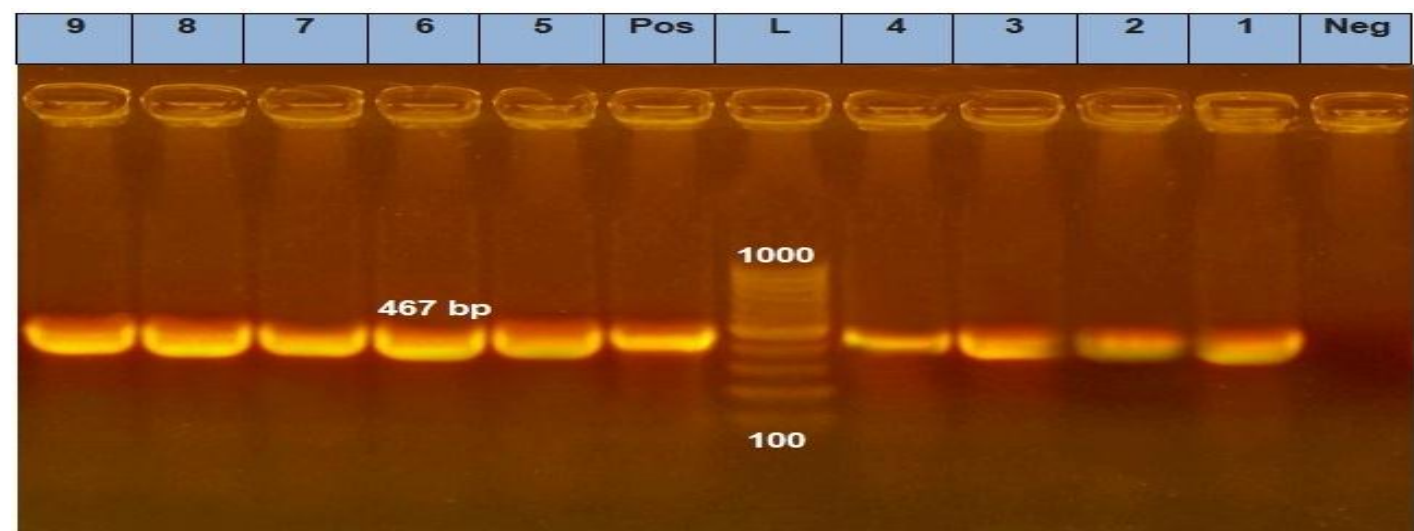

Figure (4): Agarose gel electrophoresis of PCR products after amplification of: 1- bcfC gene for salmonella strains, MWM-molecular weight marker (100 - 1000 bp DNA ladder), control (Positive, Negative) and different strains of Salmonella (bcfC gene products at $467 \mathrm{bp})$. 
Table 8: Prevalence of some virulence genes among $E$. coli strains $(n=14)$ isolated from the examined samples.

\begin{tabular}{|c|c|c|c|c|c|}
\hline \multirow{2}{*}{ E. coli strain } & \multirow{2}{*}{ Sample No. } & \multirow{2}{*}{ Total strains } & \multicolumn{3}{|c|}{ No. of detected genes } \\
\hline & & & phoA & TraT & fimH \\
\hline 026 & $\begin{array}{c}3-6-11-12- \\
13 \\
\end{array}$ & $5 / 14(35.71 \%)$ & $\begin{array}{c}5 / 5 \\
(100 \%)\end{array}$ & $\begin{array}{c}5 / 5 \\
(100 \%)\end{array}$ & $\begin{array}{c}5 / 5 \\
(100 \%)\end{array}$ \\
\hline 0119 & $7-14$ & $\begin{array}{c}2 / 14 \\
(14.28 \%) \\
\end{array}$ & $\begin{array}{c}2 / 2 \\
(100 \%) \\
\end{array}$ & $\begin{array}{c}2 / 2 \\
(100 \%) \\
\end{array}$ & $\begin{array}{c}2 / 2 \\
(100 \%)\end{array}$ \\
\hline 0125 & 4-5-9-10 & $4 / 14(28.57 \%)$ & $\begin{array}{c}4 / 4 \\
(100 \%) \\
\end{array}$ & $\begin{array}{c}4 / 4 \\
(100 \%) \\
\end{array}$ & $\begin{array}{c}4 / 4 \\
(28.57 \%) \\
\end{array}$ \\
\hline 0126 & 2 & $\begin{array}{c}1 / 14 \\
(7.14 \%)\end{array}$ & $\begin{array}{c}1 / 1 \\
(100 \%)\end{array}$ & $\begin{array}{c}1 / 1 \\
(100 \%)\end{array}$ & $\begin{array}{c}1 / 1 \\
(7.14 \%) \\
\end{array}$ \\
\hline 0127 & $1-8$ & $\begin{array}{c}2 / 14 \\
(14.28 \%) \\
\end{array}$ & $\begin{array}{c}2 / 2 \\
(100 \%) \\
\end{array}$ & $\begin{array}{c}2 / 2 \\
(100 \%) \\
\end{array}$ & $\begin{array}{c}2 / 2 \\
(14.28 \%)\end{array}$ \\
\hline Total detected gene & $\frac{\text { No. }}{\%}$ & $\begin{array}{c}14 / 14 \\
(100 \%)\end{array}$ & $\begin{array}{c}14 / 14 \\
(100 \%)\end{array}$ & $\begin{array}{c}14 / 14 \\
(100 \%)\end{array}$ & $\begin{array}{c}14 / 14 \\
(100 \%)\end{array}$ \\
\hline
\end{tabular}

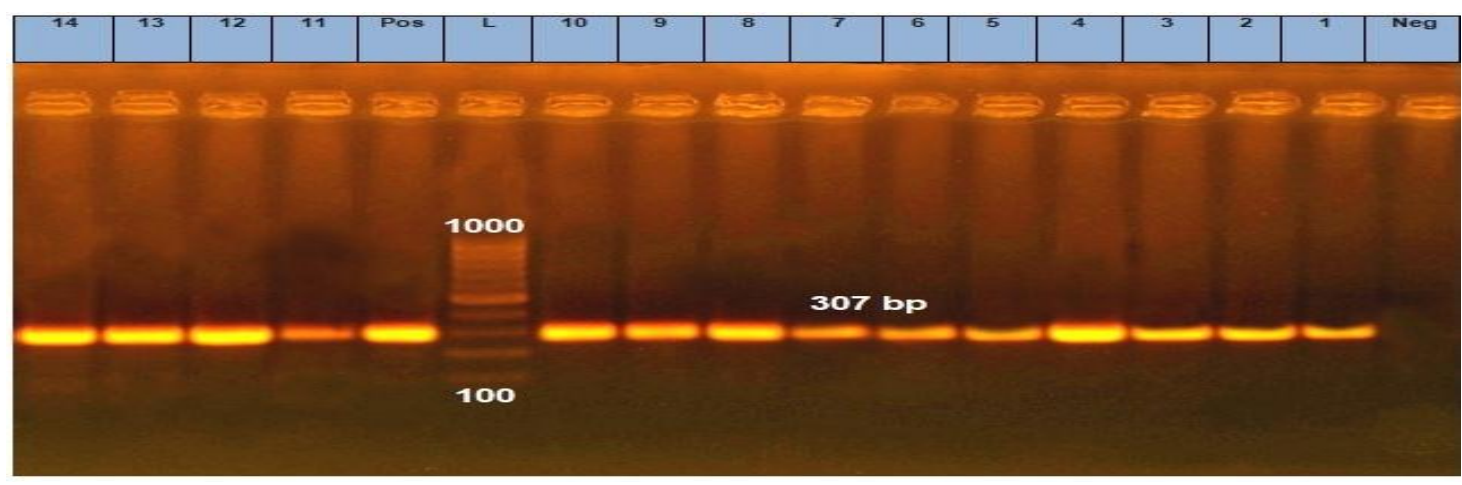

Figure (5): Agarose gel electrophoresis of PCR products after amplification of: 1- TraT gene for E. coli strains, MWM-molecular weight marker (100-1000 bp DNA ladder), control (Positive, Negative) and different strains of E. coli. (TraT gene products at $307 \mathrm{bp}$ ).

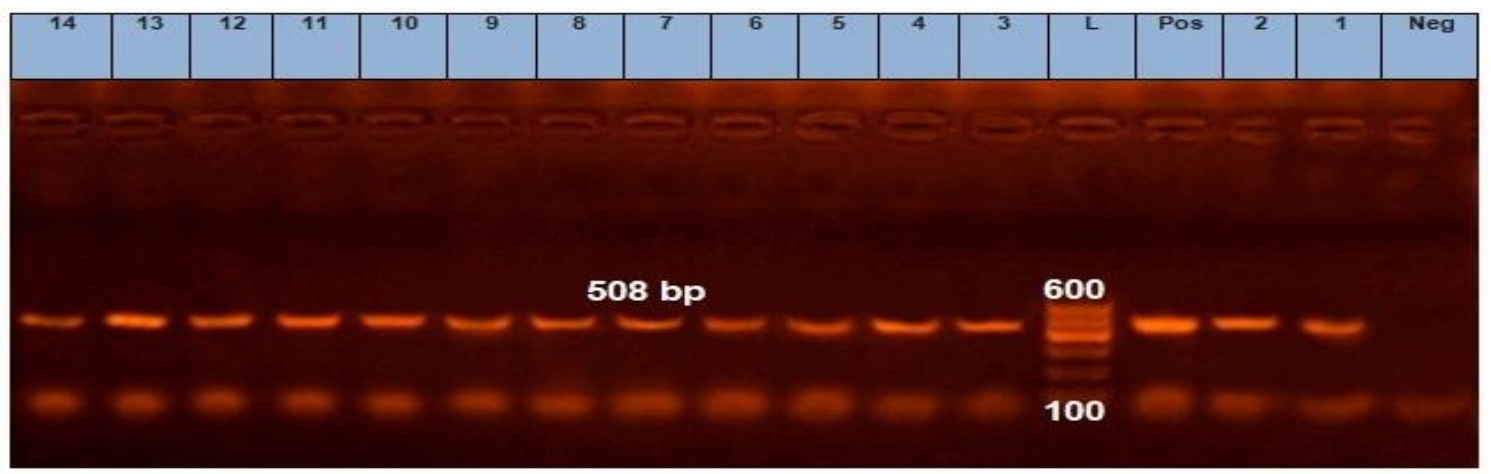

Figure (6): Agarose gel electrophoresis of PCR products after amplification of: 1- fimH gene for E. coli strains, MWM-molecular weight marker (100 - 600 bp DNA ladder), control (Positive, Negative) and different strains of $E$. coli. (fimH gene products at $508 \mathrm{bp}$ ).

Table 9: Prevalence of resistance genes among Salmonella strains $(\mathrm{n}=9)$ isolated from the examined samples.

\begin{tabular}{|c|c|c|c|c|c|}
\hline \multirow{2}{*}{ Salmonella strains } & \multirow{2}{*}{ Sample No. } & \multirow{2}{*}{ Total strains } & \multicolumn{3}{|c|}{ No. of detected genes } \\
\hline & & & ampC & mphA & $a a c C$ \\
\hline $\begin{array}{l}S . \text { Typhimurium } \\
1,4,[5], 12: \mathrm{i}: 1,2\end{array}$ & $2-3-4-5-6-9$ & $6 / 9(66.67 \%)$ & $\begin{array}{c}6 / 6 \\
(100 \%)\end{array}$ & $\begin{array}{c}3 / 6 \\
(50 \%)\end{array}$ & $\begin{array}{c}6 / 6 \\
(100 \%)\end{array}$ \\
\hline $\begin{array}{l}\text { S. Enteritidis } \\
1,9,12: \mathrm{g}, \mathrm{m}:-\end{array}$ & $7-8$ & $\begin{array}{c}2 / 9 \\
(22.22 \%) \\
\end{array}$ & $\begin{array}{c}2 / 2 \\
(100 \%) \\
\end{array}$ & $\begin{array}{c}1 / 2 \\
(50 \%) \\
\end{array}$ & $\begin{array}{c}2 / 2 \\
(100 \%) \\
\end{array}$ \\
\hline $\begin{array}{l}\text { S. Saintipaul } \\
1,4,[5], 12: \mathrm{e}, \mathrm{h}: 1,2\end{array}$ & 1 & $\begin{array}{c}1 / 9 \\
(11.11 \%) \\
\end{array}$ & $\begin{array}{c}1 / 1 \\
(100 \%) \\
\end{array}$ & $\begin{array}{c}1 / 1 \\
(100 \%) \\
\end{array}$ & $\begin{array}{c}1 / 1 \\
(100 \%) \\
\end{array}$ \\
\hline Total detected gene & $\frac{\text { No. }}{\%}$ & $\begin{array}{c}9 / 9 \\
(100 \%)\end{array}$ & $\begin{array}{c}9 / 9 \\
(100 \%)\end{array}$ & $\begin{array}{c}5 / 9 \\
(55.56 \%)\end{array}$ & $\begin{array}{c}9 / 9 \\
(100 \%)\end{array}$ \\
\hline
\end{tabular}




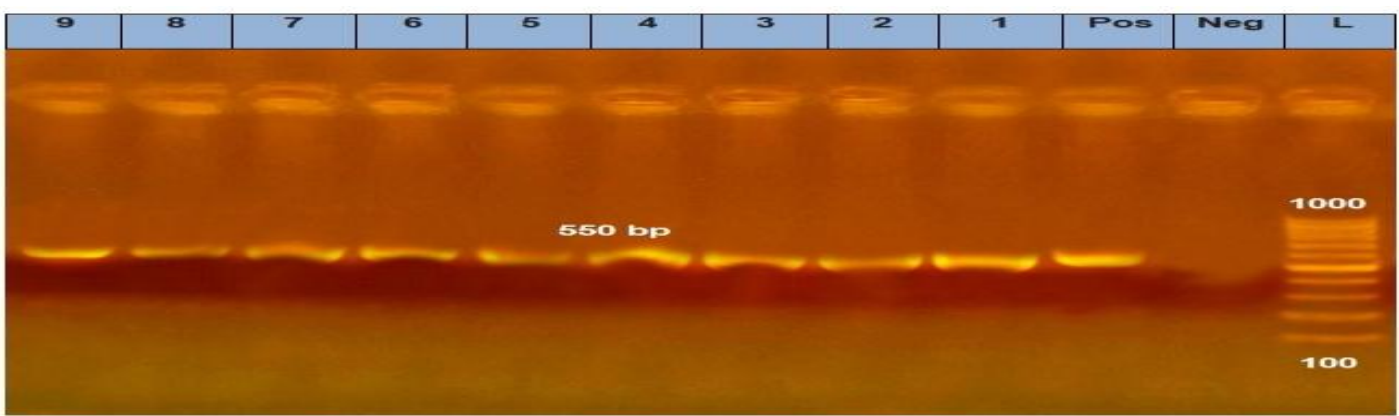

Figure (7): Agarose gel electrophoresis of PCR products after amplification of: 1- ampC gene for salmonella strains, MWM-molecular weight marker (100 - 1000 bp DNA ladder), control (Positive, Negative) and different strains of Salmonella (ampC gene products at $550 \mathrm{bp}$ )

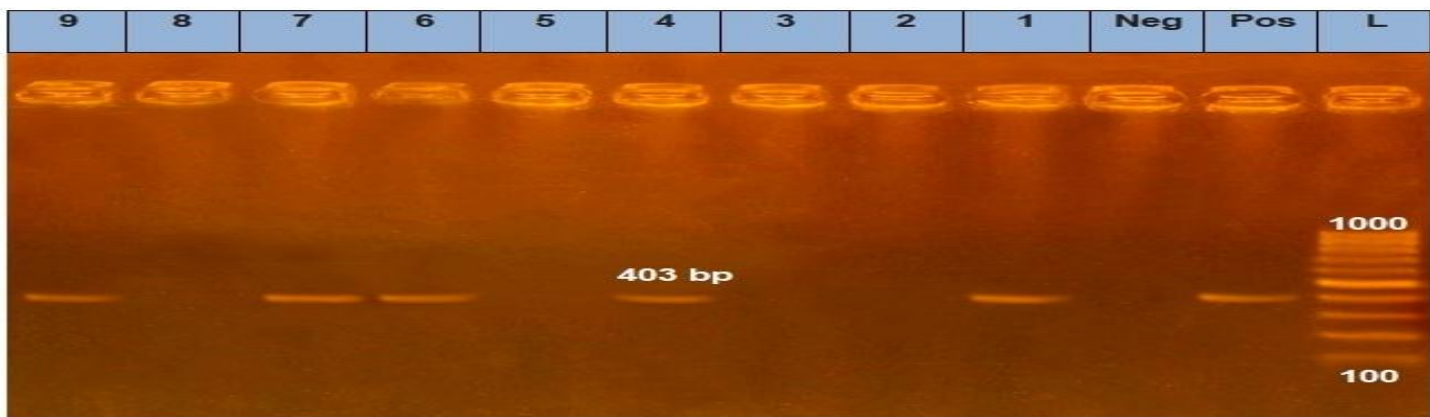

Figure (8): Agarose gel electrophoresis of PCR products after amplification of: 1- mphA gene for salmonella strains, MWM-molecular weight marker (100 - 1000 bp DNA ladder), control (Positive, Negative) and different strains of Salmonella (mphA gene products at $403 \mathrm{bp})$.

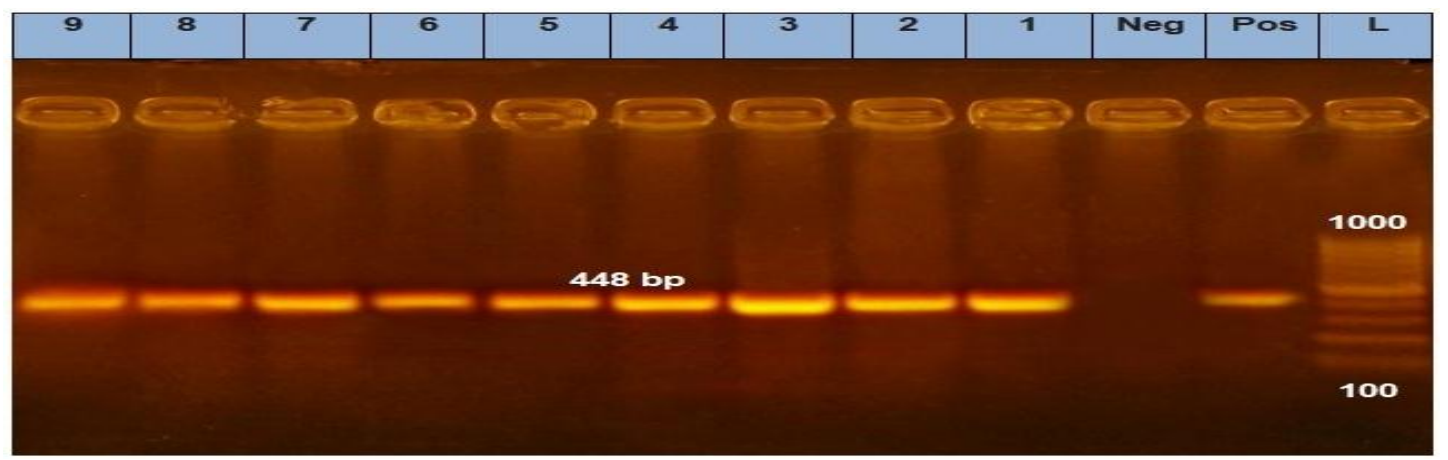

Figure (9): Agarose gel electrophoresis of PCR products after amplification of: 1- aacC gene for salmonella strains, MWM-molecular weight marker (100 - 1000 bp DNA ladder), control (Positive, Negative) and different strains of Salmonella (aacC gene products at $448 \mathrm{bp}$ ).

Table 10: Prevalence of some resistance genes among $E$. coli strains $(\mathrm{n}=14)$ isolated from the examined samples.

\begin{tabular}{|c|c|c|c|c|c|c|c|}
\hline \multirow{2}{*}{$\begin{array}{c}E . \text { coli } \\
\text { serovars }\end{array}$} & \multirow{2}{*}{$\begin{array}{c}\text { Sample } \\
\text { No. }\end{array}$} & \multirow{2}{*}{$\begin{array}{c}\text { Total } \\
\text { serovar }\end{array}$} & \multicolumn{5}{|c|}{ No. of detected genes } \\
\hline & & & blaTEm & ampC & $m p h A$ & Aada1 & $a a c C$ \\
\hline $\mathbf{O 2 6}$ & $\begin{array}{c}\text { 3-6-11- } \\
12-13\end{array}$ & $\begin{array}{c}5 / 14 \\
(35.71 \%)\end{array}$ & $\begin{array}{c}5 / 5 \\
(100 \%)\end{array}$ & $\begin{array}{c}5 / 5 \\
(100 \%)\end{array}$ & $\begin{array}{c}0 / 5 \\
(0.00 \%)\end{array}$ & $3 / 5(60 \%)$ & $\begin{array}{c}1 / 5 \\
(20 \%)\end{array}$ \\
\hline 0119 & $7-14$ & $\begin{array}{c}2 / 14 \\
(14.28 \%)\end{array}$ & $\begin{array}{c}2 / 2 \\
(100 \%)\end{array}$ & $\begin{array}{c}2 / 2 \\
(100 \%)\end{array}$ & $\begin{array}{c}0 / 2 \\
(0.00 \%)\end{array}$ & $1 / 2(50 \%)$ & $\begin{array}{c}1 / 2 \\
(50 \%)\end{array}$ \\
\hline 0125 & 4-5-9-10 & $\begin{array}{c}4 / 14 \\
(28.57 \%)\end{array}$ & $\begin{array}{c}4 / 4 \\
(100 \%)\end{array}$ & $\begin{array}{c}4 / 4 \\
(100 \%)\end{array}$ & $3 / 4(75 \%)$ & $\begin{array}{c}2 / 4 \\
(50 \%)\end{array}$ & $\begin{array}{c}0 / 4 \\
(0.00 \%)\end{array}$ \\
\hline 0126 & 2 & $\begin{array}{c}1 / 14 \\
(7.14 \%)\end{array}$ & $\begin{array}{c}1 / 1 \\
(100 \%)\end{array}$ & $\begin{array}{c}1 / 1 \\
(100 \%)\end{array}$ & $\begin{array}{c}0 / 1 \\
(0.00 \%)\end{array}$ & $\begin{array}{c}0 / 1 \\
(0.00 \%)\end{array}$ & $\begin{array}{c}0 / 1 \\
(0.00 \%)\end{array}$ \\
\hline 0127 & $1-8$ & $\begin{array}{c}2 / 14 \\
(14.28 \%)\end{array}$ & $\begin{array}{c}2 / 2 \\
(100 \%)\end{array}$ & $\begin{array}{c}2 / 2 \\
(100 \%)\end{array}$ & $\begin{array}{c}0 / 2 \\
(0.00 \%)\end{array}$ & $1 / 2(50 \%)$ & $\begin{array}{c}1 / 2 \\
(50 \%)\end{array}$ \\
\hline $\begin{array}{l}\text { Total detected } \\
\text { genes }\end{array}$ & $\frac{\text { No. }}{\%}$ & $\begin{array}{c}14 / 14 \\
(100 \%)\end{array}$ & $\begin{array}{c}14 / 14 \\
(100 \%)\end{array}$ & $\begin{array}{c}14 / 14 \\
(100 \%)\end{array}$ & $\begin{array}{c}3 / 14 \\
(21.43 \%)\end{array}$ & $\begin{array}{c}7 / 14 \\
(50 \%)\end{array}$ & $\begin{array}{c}3 / 14 \\
(21.43 \%)\end{array}$ \\
\hline
\end{tabular}




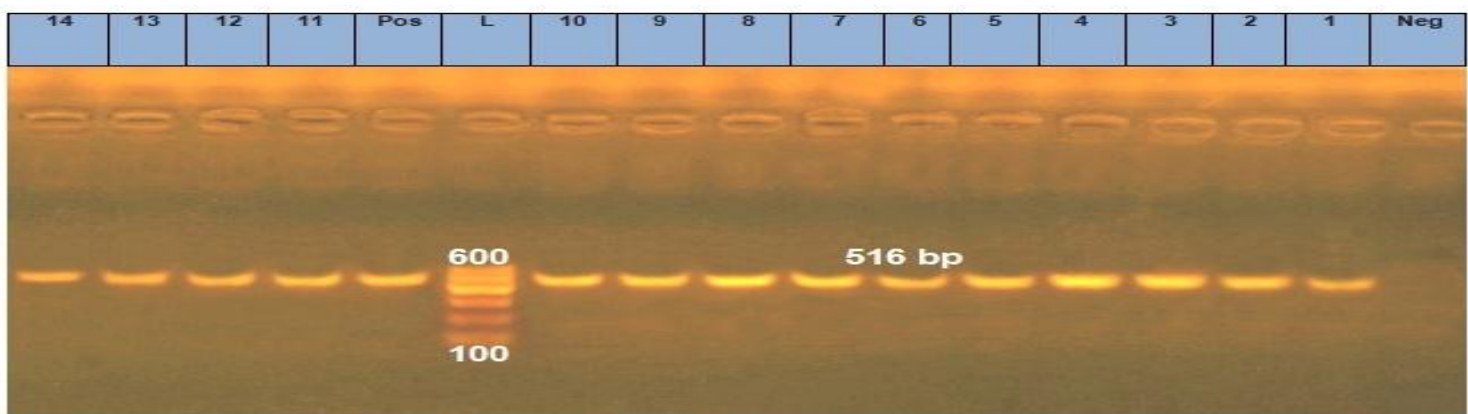

Figure (10): Agarose gel electrophoresis of PCR products after amplification of: 1- blaTEm gene for E. coli strains, MWM-molecular weight marker (100 - 600 bp DNA ladder), control (Positive, Negative) and different strains of E. coli (blaTEm gene products at $516 \mathrm{bp}$ ).

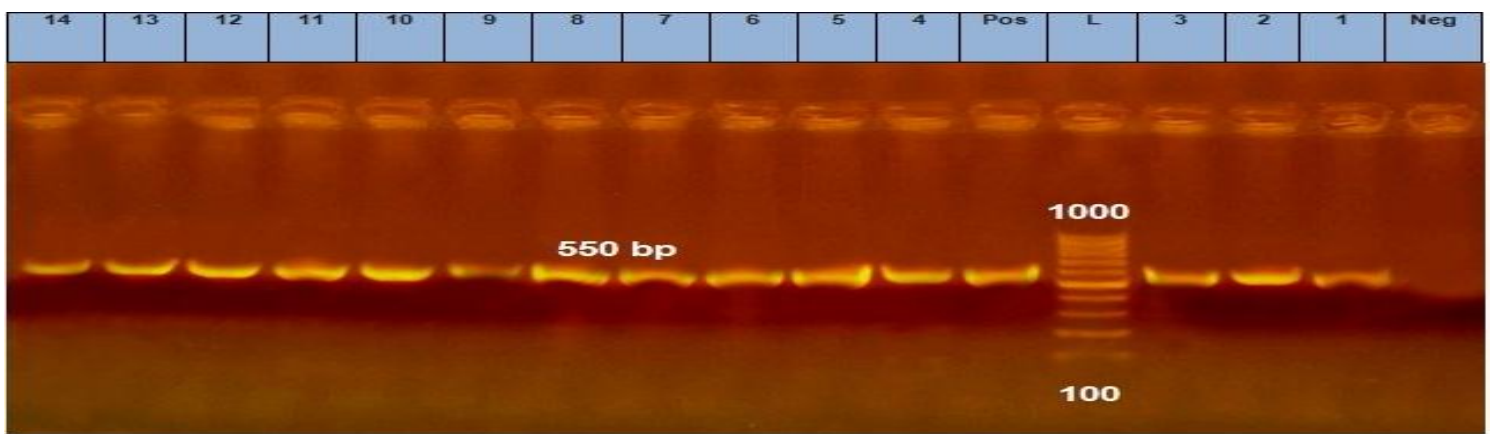

Figure (11): Agarose gel electrophoresis of PCR products after amplification of: 1- ampC gene for E. coli strains, MWM-molecular weight marker (100 - 1000 bp DNA ladder), control (Positive, Negative) and different strains of $E$. coli ( $a m p C$ gene products at $550 \mathrm{bp}$ ).

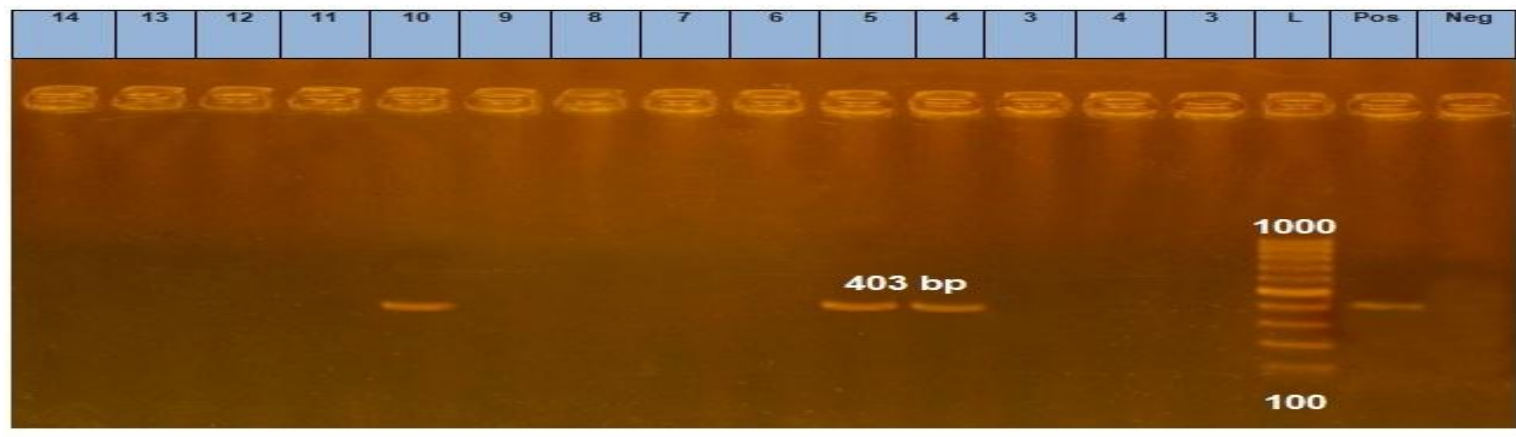

Figure (12): Agarose gel electrophoresis of PCR products after amplification of: 1- $m p h A$ gene for E. coli strains, MWM-molecular weight marker (100 - 1000 bp DNA ladder), control (Positive, Negative) and different strains of $E$. coli ( $m p h A$ gene products at $403 \mathrm{bp})$.

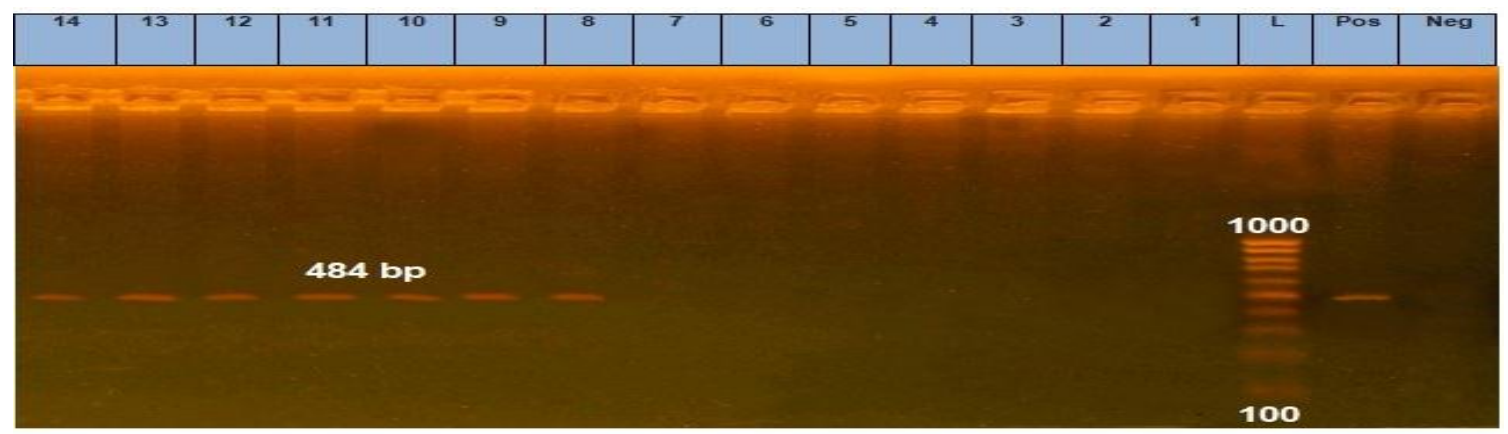

Figure (13): Agarose gel electrophoresis of PCR products after amplification of: 1- Aadal gene for E. coli strains, MWM-molecular weight marker (100 - 1000 bp DNA ladder), control (Positive, Negative) and different strains of E. coli (Aadal gene products at $484 \mathrm{bp}$ ). 


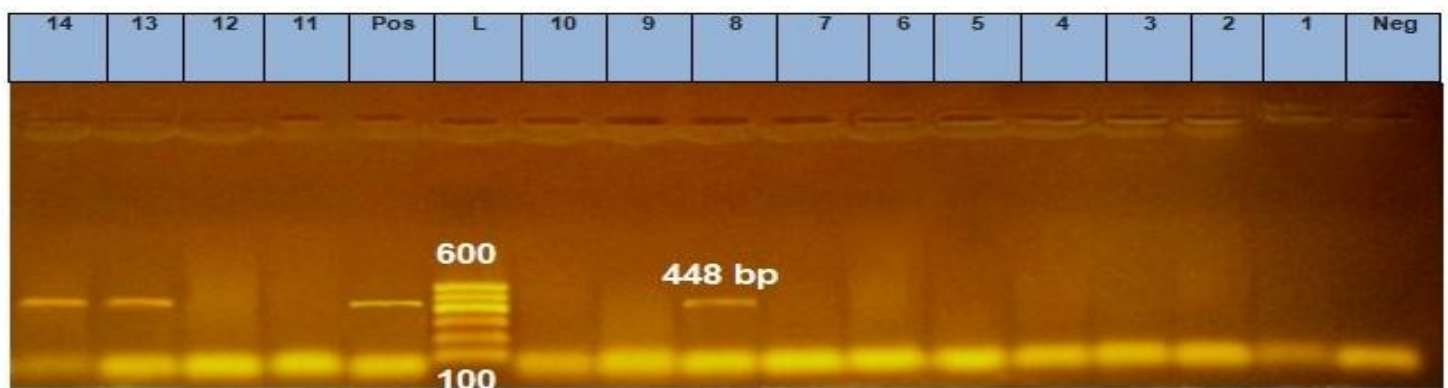

Figure (14): Agarose gel electrophoresis of PCR products after amplification of: 1- aacC gene for E. coli strains, MWM-molecular weight marker (100 - 600 bp DNA ladder), control (Positive, Negative) and different strains of $E$. coli (aacC gene products at $448 \mathrm{bp}$ ).

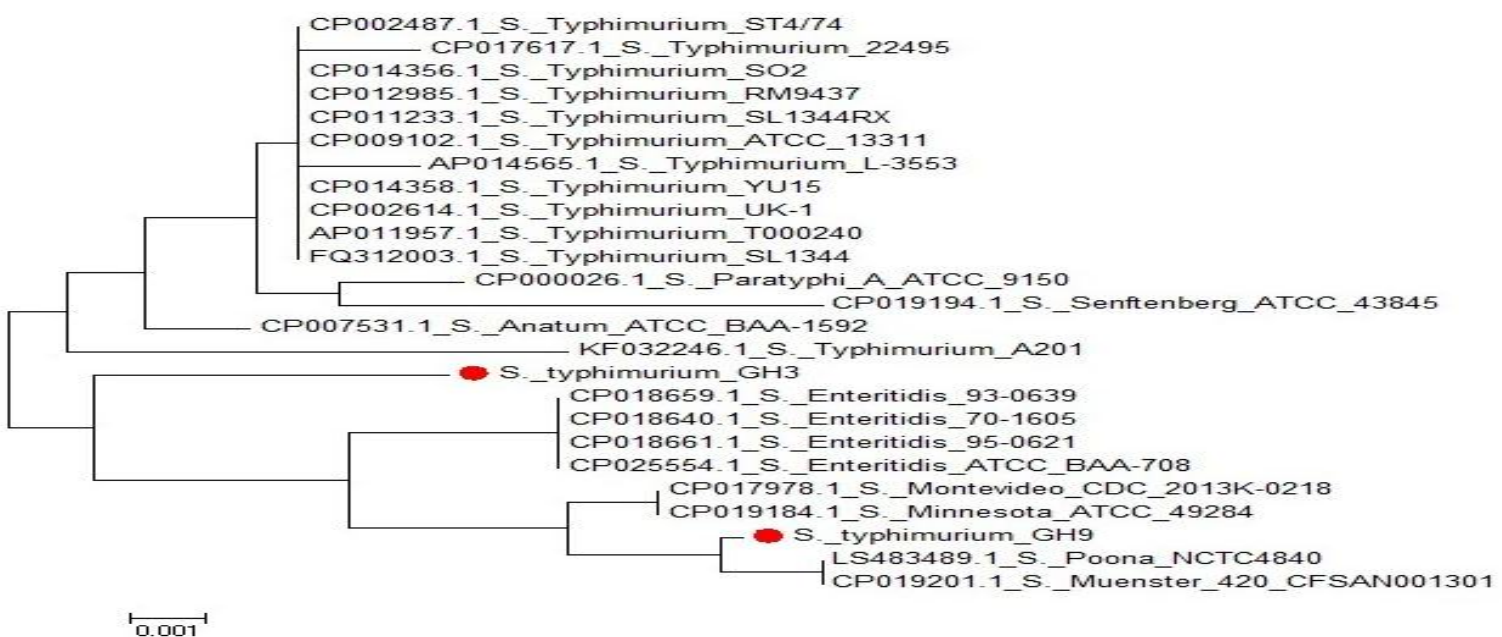

Figure (15): Phylogenic diversity tree for stn gene amino acids sequence of S. Typhimurium GH3 (sample 3) isolated from milk of cattle and $S$. Typhimurium GH9 (sample 9) isolated from fecal swabs of cattle with 23 of the most similar stn gene amino acid sequences from Gene bank.

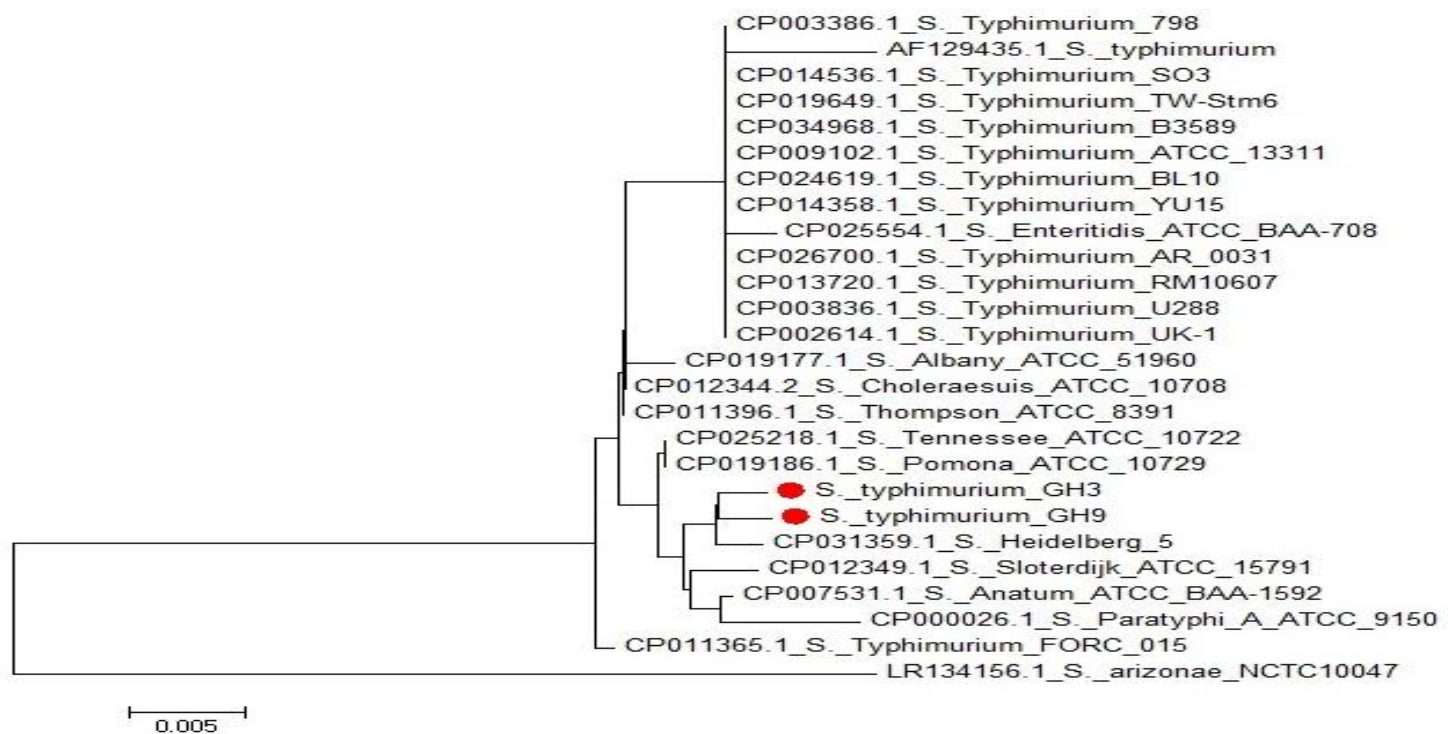

Figure (16): Phylogenic diversity tree for $b c f C$ gene amino acids sequence of $S$. Typhimurium GH3 sample 3) isolated from milk of cattle and $S$. Typhimurium GH9 (sample 9) isolated from fecal swabs of cattle with 24 of the most similar $b c f C$ gene amino acid sequences from Gene bank. 


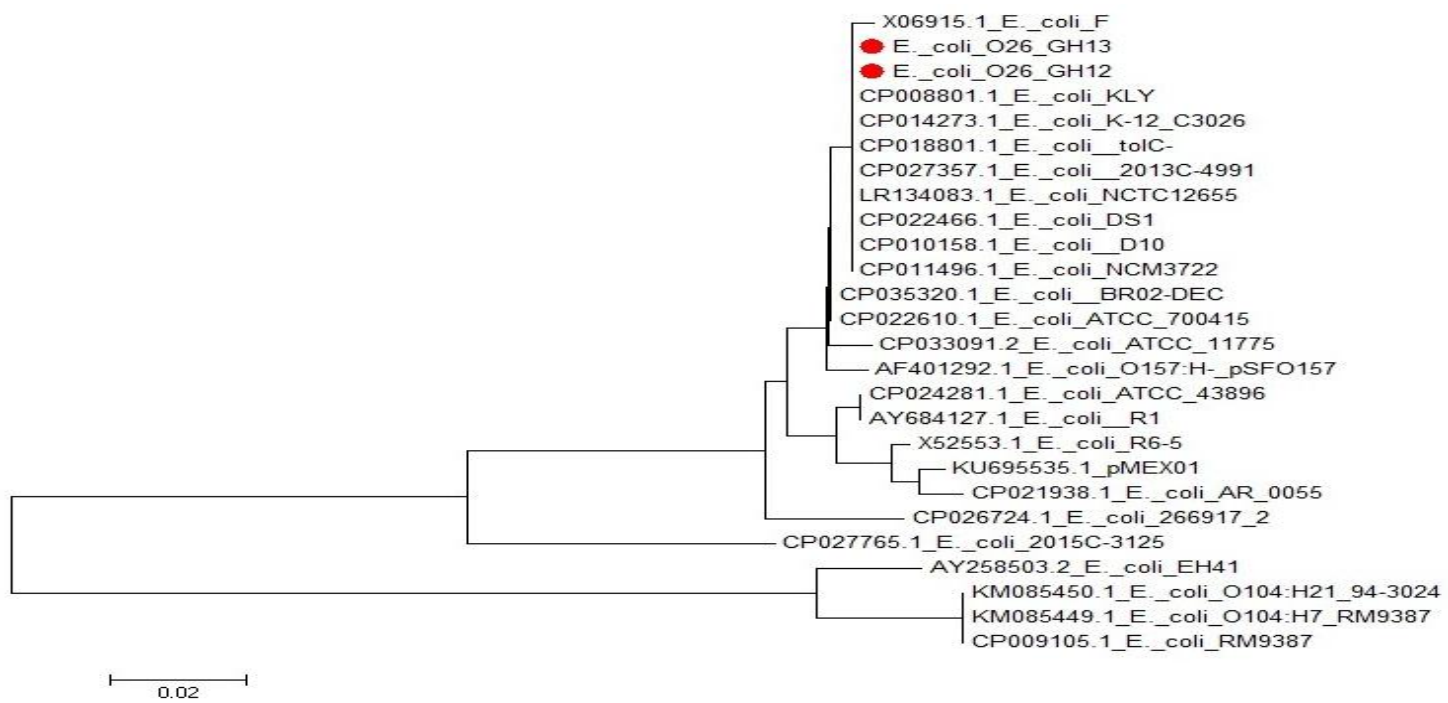

Figure (17): Phylogenic diversity tree for TraT gene amino acids sequence of E. coli O26 GH12 (sample 12) isolated from fecal swab of cattle and E. coli O26 GH13 (sample 13) isolated from fecal swab of cattle with 24 of the most similar TraT gene amino acid sequences from Gene bank.

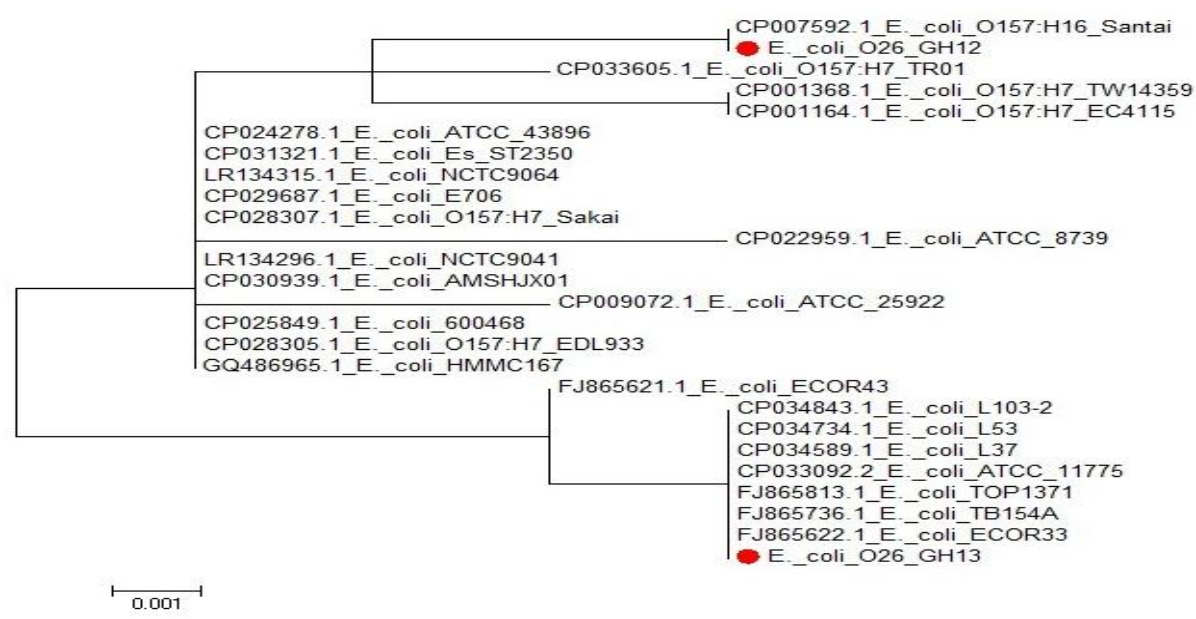

Figure (18): Phylogenic diversity tree for fimH gene amino acids sequence of E. coli O26 GH12 (sample 12) isolated from fecal swab of cattle and E. coli O26 GH13 (sample 13) isolated from fecal swab of cattle with 24 of the most similar fim $H$ gene amino acid sequences from Gene bank.

Table 11: Nucleotide change in gyrA gene of two isolates of $S$. Typhimurium.

\begin{tabular}{cccccc}
\hline \multirow{2}{*}{ Strain no. } & \multirow{2}{*}{ Serovar } & & \multicolumn{2}{c}{$\begin{array}{c}\text { Nucleotide change at gyrA Positions } \\
\text { (Mutation point) }\end{array}$} \\
\cline { 4 - 6 } & & Source & $\mathbf{8 3}$ & $\mathbf{8 7}$ & $\mathbf{1 7 9}$ \\
\cline { 3 - 6 } & & & TCC [Ser] & GAC [Asp] & TCC [Alar] \\
\hline 2 & S. Typhimurium GH2 & Feed & TTC [Phe] & None & None \\
\hline 4 & S. Typhimurium GH4 & Fecal & TTC [Phe] & None & None \\
\hline
\end{tabular}

Table (12): Nucleotide change in gyrA gene of two isolates of E. coli.

\begin{tabular}{|c|c|c|c|c|c|}
\hline \multirow[b]{2}{*}{ Strain no. } & \multirow[b]{2}{*}{ Serovar } & \multirow[b]{2}{*}{ Source } & \multicolumn{3}{|c|}{$\begin{array}{c}\begin{array}{l}\text { Nucleotide change at gyrA Positions } \\
\text { (Mutation point) }\end{array} \\
\end{array}$} \\
\hline & & & $\begin{array}{c}83 \\
\text { TCG }[\text { Ser }]\end{array}$ & $\begin{array}{c}87 \\
\text { GAC [Asp] }\end{array}$ & $\begin{array}{c}179 \\
\text { TCC [Alar] }\end{array}$ \\
\hline 3 & E. coli O26 GH3 & Feed & TTC [Leu] & None & None \\
\hline 11 & E. coli O26 GH11 & Fecal & TTC [Leu] & None & None \\
\hline
\end{tabular}




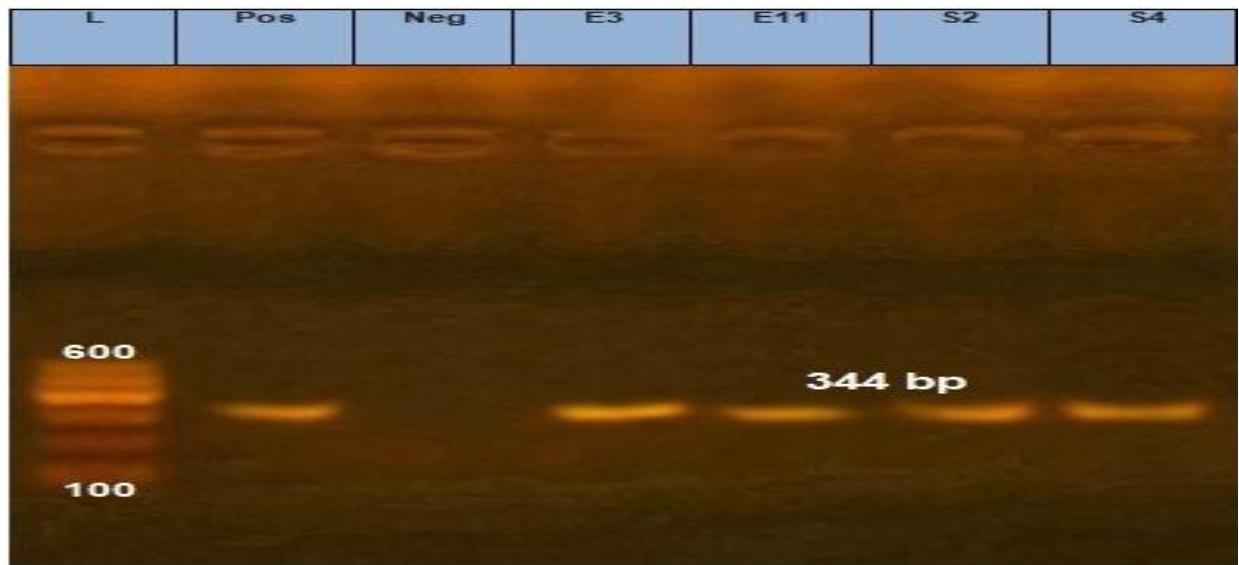

Figure (19): Agarose gel electrophoresis of PCR products after amplification of: 1- gyrA gene for $S$. Typhimurium (No. 2 and 4) and E. coli O26 (No. 3 and 11) strains, MWM-molecular weight marker (100 - 600 bp DNA ladder), control (Positive, Negative) and gyrA gene products at $344 \mathrm{bp}$ ).

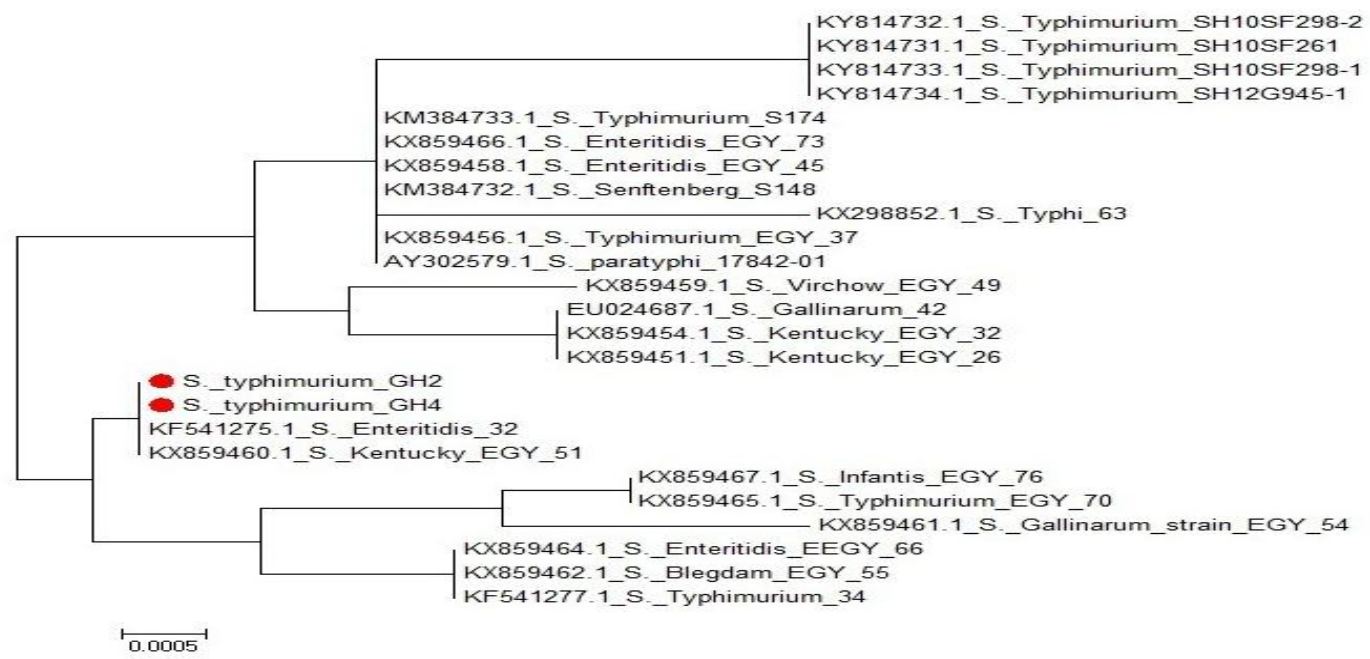

Figure (20): Phylogenic diversity tree for gyrA gene amino acids sequence of $S$. Typhimurium GH2 (sample 2) isolated from feed sample and $S$. Typhimurium GH4 (sample 4) isolated from fecal swab of cattle with 23 of the most similar gyrA gene amino acid sequences from Gene bank.

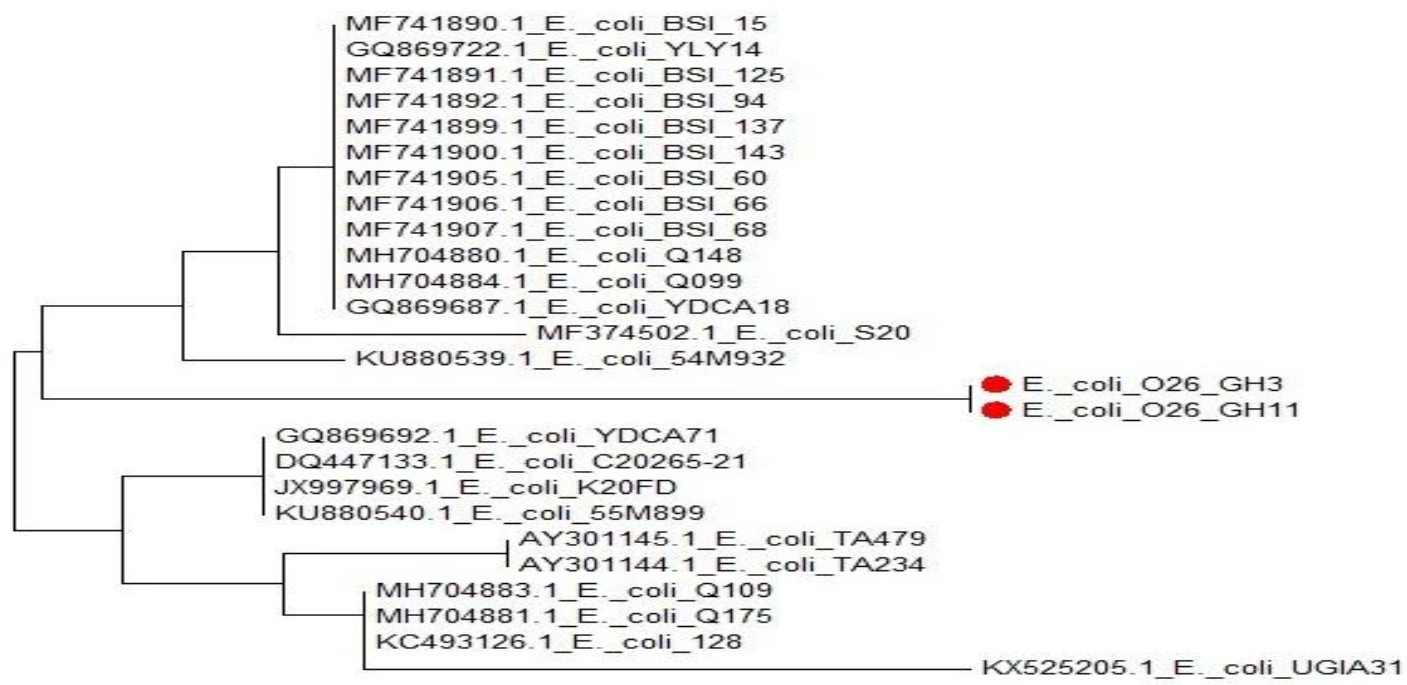

$\stackrel{5}{0.0005}$

Figure (21): Phylogenic diversity tree for gyrA gene amino acids sequence of E. coli O26GH3 (sample 3) isolated from fecal swab of cattle and E. coli O26 GH11 (sample 11) isolated from feed sample with 23 of the most similar gyrA gene amino acid sequences from Gene bank. 


\section{DISCUSSION}

For long term milk production with hygienic measures, dairy cattle should be in a good health condition (Godinho and Carvalho, 2013).

The results in Table (2) showed that the isolated Salmonella species and E. coli were found with a percentage of $1.8 \%$ and $2.8 \%$ in the total examined samples respectively. On the other hand Salmonella species in each of the examined milk, feed, milk tanks swabs, drinking tanks swabs and fecal swabs samples were found with an incidence of $1 \%, 1 \%$, $1 \%, 1 \%$ and $5 \%$, respectively, while that of $E$. coli were $2 \%, 2 \%, 1 \%, 1 \%$ and $8 \%$, respectively. These results were approximately agreed with the result recorded by Halimi et al. (2014) and Warnick et al. (2003) who found the incidence of Salmonella spp. was $1.5 \%$ and $1.1 \%$, respectively, meanwhile lower than that recorded by each of Wells et al. (2001) who found that salmonella species were isolated from fecal and milk samples with an incidence 5.4\% and $21.1 \%$, respectively, that of El-Gedawy et al. (2014) who found that the incidence of Salmonella spp. in bulk tank milk and milking equipment were $9 \%$ and $6 \%$, respectively and that of Sotohy and Khalifa (2018) who found that the incidence of the isolated Salmonella species from dairy farms was $3.2 \%$. The lower incidence may be attributed to the sample may contain other organisms that may compete with Salmonella (Karns et al., 2005). On the other hand the results were higher than that recorded by Halimi et al. (2014) who found that no Salmonella species recovered from water, feed, milk filers, and milk fed to calves. The variation between our results and that of other author's may be referred to the differences in the survival of Salmonella spp. in water, soil and pasture depending up on the differing serovars, dose rates and environmental conditions whereas Salmonella spp. can survive for up to 20 weeks in soil and water (Guan and Holley, 2003). In case of $E$. coli, our results were lower than that recorded by Abd El- Tawab et al. (2017) who found that the incidence of $E$. coli in milk collected from different localities in Egypt was 6.2\% and this may be attributed to the variation in samples types whereas our samples from apparently healthy while the other sample from mastitic milk and that recorded by Maity et al. (2010) who found the incidence of $E$. coli in fecal sample was $27.91 \%$ and the potential EPEC was $21.66 \%$.

Serological results showed in Table (3 and 4) revealed that Salmonella species were serotyped as S. Typhimurium, S. Enteritidis and S. Saintipaul and found with a percentage of $66.67 \%, 22.22 \%$ and $11.11 \%$ from the total isolated Salmonella species, respectively. $S$. Typhimurium was the predominant serotype and found in milk, feed, milk tanks swabs and the fecal swabs samples with an incidence of $16.67 \%, 16.67 \%$ and $50 \%$ respectively. The serotyped S. Enteritidis was found in drinking tanks and fecal samples with an incidence 50\% and 50\% respectively, while $S$. Saintipaul was found with an incidence of $100 \%$ in the fecal samples only. The results of the isolated $S$. Saintpaul in our results were lower than that recorded by Sotohy and Khalifa (2018) who isolates 2 strain of S. Saintpaul, one from air $4 \%$ and one from manure $2.9 \%$. $S$. Typhimurium was the predominates serotypes found with an incidence $66.67 \%$ and this attributed to the ability of $S$. Typhimurium can survive up to 28 weeks on pasture (Josland, 1951). E. coli isolates were serotyped to O26, O119, O125, O126 and O127 with an incidence $35.71 \%, 14.28 \%, 28.60 \%$, $7.14 \%$ and $14.28 \%$, respectively. This serotyped $E$. coli considered members of the enteropathogenic $E$. coli and this agree with the classification performed by WHO, (1987). The most predominant serotyped were $\mathrm{O} 26$ which found with an incidence of $80 \%$ and $20 \%$ in the fecal and feed samples respectively, followed by $\mathrm{O} 125$ which present with a percentage $25 \%$ for each of milk, feed, drinking tanks and fecal samples. The incidence of $\mathrm{O} 119$ was $50 \%$ for each of the examined milk tanks and fecal samples, while O127 was typed with an incidence of $50 \%$ for each of feed and fecal samples. The lowest incidence was O126 which present in the fecal samples only with an incidence of $100 \%$. Our results of E. coli serotyping were differed than results recorded by Sayed, (2014) who found that E. coli isolates were 18 strains (17.82\%) from 101 clinical mastitic milk samples of cows and serotyped to nine different serogroups; O111:H4 (3), O127:H6 (3), O26 (2), O126 (2), O119:H6 (1), O114:H21 (1), O55:H7 (1), O44:H18 (1), O124 (1) and (3) untyped. Also differed than that of Abd El-Tawab et al. (2017) who found that $E$. coli serotypes were 15 typed as O27, O146, O125, O126, O111, O20 and O157 and 2 untyped. This variation was attributed the difference in in their natural reservoir (Foley et al., 2008).

By agar disk diffusion method, antibiotic sensitivity test were applied against the isolated Salmonella $(\mathrm{n}=9)$ and E. coli $(\mathrm{n}=14)$ strains and recorded in Table (5). The results revealed that Salmonella and E. coli strains have led to development of resistance to antimicrobial agents which originally effective against the examined microbes. Salmonella strains showed $100 \%$ resistance against ceftroiaxon; gentamicin; lioncomycin and vancomycin. Also Salmonella strains showed a resistance against oxolinic acid; penicillin $\mathrm{G}$ and streptomycin; with an incidence $88.89 \%, \quad 77.78 \%$ and $88.89 \%$, respectively. While the incidence of resistance Salmonella strains against erythromycin; oxytetracycline; trimethoprim + sulphamethoxazole were $55.56 \%, 33.33 \%$ and $22.22 \%$, respectively. Our results showed multi-drugs resistance as recorded by Halimi et al. (2014) and agree with the results recorded by Tamba et al. (2016) who found 
that all isolates of Salmonella showed $100 \%$ resistance to lincomycin. Also our resistance results of Salmonella species against oxytetracycline were lower than that recorded by Halimi et al. (2014) who found that $94.74 \%$ of salmonella species were resistance to oxytetracycline and that of Tamba et al. (2016) who recorded that $85.71 \%$ of Salmonella species were resistance to erythromycin. On the other hand, our results were higher than that of Mohamed et al. (2011) who found that $14.3 \%$ of Salmonella strains were resistant to gentamycin, that of Wells et al. (2001) who recorded that $0.1 \%$ of Salmonella strains were resistant to gentamycin. The difference between our results and the results recorded by Halimi et al. (2014) come back to the differences between farms in the frequency of usages, widespread and inappropriate usage of oxytetracycline in dairy operations and dairy farms and association with fecal shedding.

Also the resistance of E. coli strain against ceftroiaxon; lioncomycin; oxolinic acid; penicillin $\mathrm{G}$ and vancomycin were highly resistance and found with incidence $100 \%, 100 \%, 100 \%, 100 \%$ and $85.71 \%$, respectively, while the resistance against erythromycin; gentamicin; oxytetracycline; streptomycin and trimethoprim + sulphamethoxazole were $21.42 \%, 21.42 \%, 35.71 \%, 50.00 \%$ and 14.30 $\%$, respectively. Our results showed multi-drugs resistance as recorded by Abd El- Tawab et al. (2017) and Yassin et al. (2017). On the other hand our results varied with the results recorded by other authors whereas my results were lower than that of Abd El- Tawab et al. (2017) who found that the incidence of resistance against gentamicin; oxytetracycline and streptomycin were $30 \%, 70 \%$ and $100 \%$, respectively, while a higher than the resistance against penicillin $\mathrm{G}(80 \%)$ recorded by Abd El- Tawab et al. (2017) and also higher than that recorded by Yassin et al. (2017) who found that the incidence of resistance against gentamicin; streptomycin; ceftroiaxon and trimethoprim + sulphamethoxazole were $8.2 \%, 18.0 \%, 4.9 \%$ and $18.0 \%$, respectively. The variation in the incidence of resistance against antibacterial between our results and the results of other authors were referred to the variation between the use and misuse of antimicrobials in farm animals (Sawant et al., 2007).

All serotyped Salmonella (No. =9) and E. coli (No. $=14$ ) were conducted for molecular characterization by conventional PCR Table (6) and Fig. (1and2). Firstly, confirmation of Salmonella and E. coli applied by detection of invA gene (at $284 \mathrm{bp}$ ) and phoA gene (at $720 \mathrm{bp}$ ) which were found with an incidence $100 \%$ and $100 \%$, respectively. These results agree with results reported by Sotohy and Khalifa (2018) who found that invA (at284 bp) virulence and conformity gene was found in all isolated Salmonella strains. In this study invA gene was used as confirmatory genes for genus
Salmonella due to the invA gene of Salmonella species contains unique sequences to this genus and has been proved to be a suitable PCR target with potential diagnostic application (Jamshidi et al., 2008). invA gene is recognized as an international standard for detection of Salmonella genus (Malorny et al., 2003). On the other hand phoA genes was selected to confirm the detection of $E$. coli strains and this results agree with result recorded by Kong et al. (1995); Kong et al. (1999) and Yu and Thong, (2009) who performed the confirmation of E. coli by detection of phoA gene at $720 \mathrm{bp}$. which present in all E. coli strains.

The results in Table (7) and Fig. (1, 3 and 4) showed that the incidences of each of the studied invA (at 284 bp), stn (at 617 bp) and $b c f C$ (at 467 bp) virulence genes were detected in $100 \%$ of each of the isolated $S$. Typhimurium, S. Enteritidis and S. Saintipaul). The incidence of each of $i n v A$ gene, stn gene and $b c f C$ gene in all isolated Salmonella species were $66.67 \%, 22.22 \%$ and $11.11 \%$, for $S$. Typhimurium, S. Enteritidis and S. Saintipaul respectively. Our results showed that the virulence invA, stn gene and $b c f C$ gene were detected in all of the isolated salmonella strains and this was disagree with results recorded by Sotohy and Khalifa (2018) who found only invA (at $284 \mathrm{bp}$ ) virulent gene was detected in $S$. Saintipaul. This variation was attributed the difference in their natural reservoir (Foley et al., 2008).

Our results of stn gene were higher than that of Maysa and Abd-Elall (2015) who found that stn were detected in $S$. Typhimurium and $S$. Enteritidis with incidence of $78.9 \%$ and $75 \%$, respectively. Our results of $b c f C$ were agree with the results recorded by Maysa and Abd-Elall (2015) who found that $b c f C$ was detected in $100 \%$ of $S$. Enteritidis, while higher than that of Maysa and Abd-Elall (2015) who found $b c f C$ in $88.9 \%$ of the isolated $S$. Typhimurium. The variation between our results and results recorded by other authors were regarded to widely distribution of the microorganisms among animals, humans and environment and some diversity in distribution could be explained by serovar specificity of virulence plasmid (Heithoff et al., 1997 and Rotger and Casadesus, 1999).

The studied phoA (at $720 \mathrm{bp}$ ), TraT (at $307 \mathrm{bp)}$ and fimH (at $508 \mathrm{bp}$ ) virulence genes of the isolated $E$. coli present in Table (2) and Fig. (2, 5 and 6) were detected in $100 \%$ of each the isolated E. coli serotypes. Each of phoA gene, TraT gene and fimH gene were detected in all serotyped $E$. coli with incidences $35.71 \%, 14.28 \%, 28.57 \%, 7.14 \%$ and $14.28 \%$, for $\mathrm{O} 26, \mathrm{O} 119, \mathrm{O} 125, \mathrm{O} 126$ and $\mathrm{O} 127$ respectively. The phoA gene (at 720 bp) was detected in $E$. coli strains and this result agrees with result recorded by $\mathrm{Hu}$ et al. (2011) and Alnahass et al. (2016). 
Our results of the detection of TraT gene were higher than that recorded by each of Ashraf et al. (2018) who found that the incidence of TraT in the isolated E. coli was $66 \%$, that of Nemeth et al. (1991) who found that the incidence of TraT in the isolated E. coli from mastitic milk and milk filler samples were $43 \%$ and $40 \%$, respectively and that recorded by Mahmoud et al. (2015) who found that the incidence of TraT gene was $25 \%$. Our results of fimH gene agree with the results recorded by Fernandes et al. (2011) and Abd El-Tawab et al. (2017) who found that the incidence of fimH in all strains of the isolated E. coli were $100 \%$. The incidence of fimH in $\mathrm{O} 125$ and $\mathrm{O} 126$ were agreed with the results recorded by Abd El- Tawab et al. (2017). Our results were higher than the results recorded by Bronzato et al. (2017) who detected fimH with incidence $77.7 \%$ in isolated $E$. coli strain. This variation may be due to difference in the percentage of dispersion of microorganism in the dairy farm environment and horizontal gene transfer (Madsen et al., 2012).

The detected resistance genes in Table (9) and Fig. (7, 8 and 9) showed that each $a m p C$ gene (at $550 \mathrm{bp}$ ) and $a a c C$ gene (at $448 \mathrm{bp}$ ) were detected in $100 \%$ of each of the isolated $S$. Typhimurium, $S$. Enteritidis and S. Saintipaul, while $m p h A$ gene (at 403 bp) was detected in each of $S$. Typhimurium, S. Enteritidis and S. Saintipaul, with an incidence 50\%, 50\% and $100 \%$ respectively. The incidences of each ampC gene and aacC gene in all isolated Salmonella species were $66.67 \%, 22.22 \%$ and $11.11 \%$, for $S$. Typhimurium, S. Enteritidis and S. Saintipaul respectively, while $m p h A$ gene was detected in all Salmonella strain with an incidence $55.56 \%$. Our result for resistance $m p h A$ gene (at $403 \mathrm{bp}$ ) for the isolated Salmonella strain were higher than that recorded by Wang et al. (2017) who detected the mphA gene with a percentage of $48.39 \%$ of resistant Salmonella isolates and that of Abdel Aziz et al. (2018) who found that the $m p h A$ resistance gene cassette was detected in $41.7 \%$ of isolated salmonella showed multidrug resistance. Also our results of ampC gene (at $550 \mathrm{bp}$ ) was higher than that recorded by Zhao et al. (2008) who found that ampC resistance gene was detected in Salmonella species isolated from ground turkey meat and chicken breast with a percentage of $46.67 \%$ and $11.11 \%$, respectively. Also higher than that cited by Public Health Agency of Canada (2007) whereas ampC resistance gene was detected in approximately $30 \%$ of salmonella isolates in 2003 and the prevalence was gradually increased to approximately $48 \%$ in the second quarter of 2005. The results of aacC gene (at $448 \mathrm{bp}$ ) was higher than that of Randall et al. (2004) and Lynne et al. (2008) who recorded that $a a c C$ was detected in $71.43 \%$ and $42.90 \%$ (3) isolates, respectively.
While the detected resistance genes of $E$. coli in Table (10) and Fig. (10, 11, 12, 13 and 14) showed that blaTEm gene (at $516 \mathrm{bp}$ ) and $\operatorname{ampC}$ gene (at 550 bp) resistance genes were found in $100 \%$ of each the isolated E. coli serotypes while that of $m p h A$ gene (at $403 \mathrm{bp}$ ), Aadal gene (at $484 \mathrm{bp)}$ ) and $a a c C$ gene (at $448 \mathrm{bp}$ ) resistance genes were found in $21.43 \%$, $50.00 \%$ and $21.43 \%$, respectively. Each of blaTEm gene and $a m p C$ gene resistance genes were detected in each of O26, O119, O125, O126 and O127 with an incidence $35.71 \%, 14.28 \%, 28.57 \%, 7.14 \%$ and $14.28 \%$, respectively, while $m p h A$ gene was detected only in $\mathrm{O} 125$ with incidence of $75 \%$. Also the results revealed that Aadal resistance gene was detected in O26, O119, O125 and O127 with an incidence of $60 \%, 50 \%, 50 \%$ and $50 \%$, respectively. Meanwhile aac $\mathrm{Cene}$ was found with incidence of $20 \%, 50 \%$ and $50 \%$ in $\mathrm{O} 26, \mathrm{O} 119$ and $\mathrm{O} 127$ respectively. Our results agree with results recorded by Hussein et al. (2008) who found $m p h A$ resistance genes in a percentage $100 \%$ of the isolated E. coli. Meanwhile the results of the resistance_blaTEm gene (at $516 \mathrm{bp}$ ), $\operatorname{ampC}$ gene (at $550 \mathrm{bp}$ ) and Aadal genes (at $484 \mathrm{bp}$ ) were higher than that recorded by Ashraf et al. (2018) who found that the blaTEm, ampC and Aadal genes were detected with a percentage of $4 \%$ and $26 \%$ and $12 \%$ of the isolated E. coli respectively. Also higher than that of Hinthong et al. (2017) who detected blaTEm, Aadal and aacC gene with a percentage of $61.3 \%, 3.3 \%$ and $4.9 \%$, respectively and that of Wassef et al. (2014) who detected the $a m p C$ gene in the isolated $E$. coli with a percentage $66.7 \%$. The variation between results may regards to geographical discrepancy in ampC $\beta$ lactamase types Pai et al. (2004). In general the variation between results was regarded to the dissemination of strains carrying resistance genes for antimicrobials whereas the antimicrobial drugs as aminoglycosides, beta-lactams, tetracycline chloramphenicol, sulfonamides, and trimethoprim has been acquired by E. coli strains from other microorganisms (Lietzau et al., 2006).

In Fig. (15 and 16), DNA Sequence was initially performed to establish sequence identity to Gene Bank accessions. $S$. Typhimurium GH3 and $S$. Typhimurium GH9 were selected to study the similarity of virulence $s t n$ gene and $b c f C$ gene with other types in Gene bank, while in Fig. (17 and 18), E. coli $\mathrm{O} 26 \mathrm{GH} 12$ and E. coli $\mathrm{O} 26 \mathrm{GH} 13$ were selected to study the similarity of virulence fimH gene and TraT gene with other types in Gene bank. Sequence alignments using the NCBI BLASTP program showed that of $S$. Typhimurium GH3 virulence stn had high genetic similarity (99.4\%) of S. Enteritidis with accession-numbers: Cp018659.1 _S._ Enteritidis_93-0639 \& Cp018640.1_S._ Enteritidis_70-1605 \& Cp018661.1_S._ Enteritidis_ 95-0621 \& Cp025554.1_S._ Enteritidis_ATCC_ BAA-708, while $S$. Typhimurium GH9 virulence $s t n$ had height genetic similarity with LS483489.1_S_ 
Poona_NCTC4840 and CP019201.1_S_ Muenster _420_CFSAN001201.

While $S$. Typhimurium GH3 virulence $b c f c$ showed a high percentage of genetic similarity $(99.6 \%)$ with accession-numbers: Cp031359.1_S._Heidelberg_5 \& Cp012349.1_S._Slotedijk_ATCC_15791 \& Cp019186.1_S._Pomona_ATCC_10722.

On the other hand the E. coli $\mathrm{O} 26 \mathrm{GH} 12$ and E. coli O26 GH13 virulence TraT were agree with other $E$. coli with accession-numbers: X06915.1_E._coli_F and Cp014273.1_E._coli_K_12_C3026 with a percentage of $99.7 \%$ and $100 \%$ respectively. While E. coli $\mathrm{O} 26 \mathrm{GH} 12$ virulence fimH was highly genetic similarity with accession-numbers: Cp007592.1_E._coli_O157:H16_Saintai \& Cp001368.1_E._coli_O157:H7_TW14359 \& Cp001164.1_E_coli_O157:H7_EC4115 with a percentage $98.4 \%$ for each one. Also E. coli $\mathrm{O} 26$ GH13 virulence fimH had a highly genetic similarity with E. coli with accession-numbers: Cp034843.1_E_coli_L103-2, Cp034734.1_E_coli_ L53, Cp033092.1_E_coli_ATCC_117755, FJ865813.1_E_coli_Top1371, $\quad$ FJ865736.1_E _coli_TB154A and FJ865622.1_E_coli_ECOR33.

Sequence alignments of antimicrobial resistance gene as $g y r A$ (at $344 \mathrm{bp}$ ) for both $S$. Typhimurium and $E$. coli $\mathrm{O} 26$ were performed by the NCBI BLASTP program after confirmation by PCR as showed in fig. (19). The main principle was the detection of the substitutions in terms of amino acid positions gyrA Ser 83, gyrA Asp 87 and gyrA Alar 179, which are located within the QRDR. The mutations induced a local conformation changes of the A subunits cause marked resistance to specific antibiotic as quinolones. On studied of the selected 2 strains of Salmonella, $S$. Typhimurium GH2 and $S$. Typhimurium GH4 in Table (11) and Fig.(20) showed that amino acid changes detected at amino acid 83 were Ser changed to phe results in one point mutant. Also the selected E._coli_O26_GH3 and E._coli_O26_GH13 in Table (12) and Fig.(21) had one point mutation at amino acid 83 whereas Ser changes into Leu. Our results agree with the results recorded by Yoshida et al. (1988) who found that amino acid changes detected in amino acid 83 and the point mutations in codon TCG at Ser 83 and with the results recorded by Nakamura et al. (1989) who found that Mutations in the $g y r A$ and $g y r B$ subunits of DNA gyrase play a major role in conferring a high level of resistance to fluoroquinolone in Gramnegative bacteria, such as $E$. coli while the mutations in gyrA gene (at $344 \mathrm{bp}$ ) are more common in quinolone resistance of $E$. coli.

In this study some virulence genes of both Salmonella species and E. coli were detected but no records of symptoms within the examined dairy cattle herds, this referred to the pathogenicity is not dependent on one virulence factor but occurred due to the regulation and interaction between a numbers of virulence factors that affected by environmental conditions as host species, species stress, host health status, immune status of the individual, interaction with other bacteria, the infecting dose, the method of delivery of the organisms to the host. Therefore the examined dairy cattle herds considered carrier animals that shed and spread the Salmonella and E. coli microorganisms in the feces, milk and/or environment after ingestion feed or water contaminated with feces from other carrier or infected animals (cross contamination). Also the detected resistance genes regards to a problem in the role of corrected treatments. Thus we concluded that strictly purchasing cattle from good source, with its life history from birth, vaccination, treatment and diseases history, not from dealers of unknown sources. Strict control of the environment of farms by preventing contacts between dairy cattle, calves and the other carrier species such as dogs, birds, cats, people, pig, feral cats and wild birds. Also prevent contacts between the different carrier species and feed, water and all equipment used in the production of milk especially feral cats and wild birds. Only good sources of feed and good sources of water were used in the farms. Awareness should be created among the dairy farmers on the transmission of various diseases from dairy environment to dairy cattle and the preventive measures used. Governorates should cite the supervision of veterinarian in farms is strictly. Strict hygienic measures were applied during the waste management and effluent control. Antimicrobial drugs should be used when needed with an accurate dose, in specific times and for specific cases during a certain period under the supervisions of veterinarian. Applied the recommendations and the hygienic measurement of HACCP, biosafety and biosecurity for dairy farms especially for water, soil, udder, unhygienic milking utensil, and Milkers' hands to obtain a good health dairy cattle and calves and good hygienic safe milk for consumers.

\section{REFERENCES}

Abd El-Tawab, A.A.; Nabih, A.M.; Agag, M.A. and Al-Abbou, M.A. (2017): Bacteriological and molecular studies on Shiga-Toxin producing Escherichia coli causing cattle clinical mastitis. Benha veterinary medical journal, 33(2): 17-26.

Abdel Aziz, S.A.; Abdel-Latef, G.K.; Shany, S.A.S. and Rouby, S.R. (2018): Molecular detection of integron and antimicrobial resistance genes in multidrug resistant Salmonella isolated from poultry, calves and human in Beni-Suef governorate, Egypt. Beni-Suef University Journal of Basic and Applied Sciences, 7 (4): 535-542. 
Achá,

$$
\text { S.J.; }
$$

Kuhn, I.;

Jonsson, P.; Mbazima, G.; Katouli, M. and Mollby, R.S. (2004): Studies on calf diarrhoea in Mozambique: prevalence of bacterial pathogens. Acta. Vet. Scand, 45: 27-36.

Agüero, M.E.; Aron, L.; Deluca, A.G.; Timmis, K.N. and Cabello, F.C. (1984): A plasmidencoded outer membrane protein, TraT, enhances resistance of Escherichia coli to phagocytosis. Infection and Immunity, 46: 740-746.

Alnahass, R.; Khaliel, S.; Ellakany, H. and Ibrahim, S.M. (2016): Comparison between bacteriological isolation and molecular detection of $E$. coli from chickens suffering from colibacillosis and/or diarrhea. Alexandria Journal of Veterinary Sciences, 49(2): 141-148.

Altschul, S.F.; Gish, W.; Miller, W.; Myers, E.W. and Lipmanl, D.J. (1990): Basic Local Alignment Search Tool. J. Mol. Biol., 215: 403-410.

Ashraf, A.; Imran, M. and Chang, Y.F. (2018): Antimicrobial resistance of Escherichia coli isolates from mastitic milk and its possible relationship with resistance and virulence genes. Pakistan J. Zool., 50(4):1435-1441.

Barrow, P.A.; Jones, M.A. and Thomson, N. (2010): Salmonella. In Pathogenesis of bacterial infections in animals. Edited by Gyles, C.L.; Prescott, J.F.; Songer, J.G. and Thoen, C.O. Ames: Blackwell Publishing: 231-265.

Bronzato, G.F.; Rodrigues, N.M.B.; Pribul, B.R.; Santiago, G.S.; Coelho, I.S.; de Souza, M.M.S.; Reinoso, E.; Lasagno, M. and Coelho, S.M.O. (2017): Genotypic characterization of Escherichia coli strains isolated from dairy cattle environment. African Journal of Microbiology Research, 11(47):1669-1675.

Buller, N.; Annette, T. and Mary, B. (2014): Antibiotic susceptibility testing Australia and New Zealand Standard Diagnostic Procedures, 1-30.

Cabral, J.F.; da Silva, M.A.P.; Carvalho, T.S.; Brasil, R.B.; Garcia, J.C.; Neves, R.B.S.; Nicolau, E.S. and Moacir Evandro Lage, M.E. (2015): Procedure for collecting milk sample and the number of milkings in relation to chemical composition and somatic cells of the fresh milk. African Journal of Agricultural Research, 10(50): 4623-4631.

Callaway, T.R.; Keen, J.E.; Edrington, T.S.; Baumgard, L.H.; Spicer, L.E.; Fonda, S.; Griswold, K.E.; Overton, T.R.; Van Amburgh, M.E.; Anderson, R.C.; Genovese, K.J.; Poole, T.L.; Harvey, R.B. and Nisbet, D.J. (2005): Fecal prevalence and diversity of Salmonella species in lactating dairy cattle in four states. J. Dairy Sc., 88: 3603-8.
Centers for Disease Control and Prevention "CDC", (2011): Escherichia coli O157:H7.

Chang, C.N.; Kuang, W.J. and Chen, E.Y. (1986): Nucleotide sequence of alkaline phosphatase gene of Escherichia coli. Gene 44 (1): 121125.

Chassaing, B.; Rolhion, N.; de Vallée, A.; Salim, S.Y.; Prorok-Hamon, M.; Neut, C.; Campbell, B.J.; Söderholm, J.D.; Hugot, JP.; Colombel, J.F. and Darfeuille-Michaud, A. (2011): Crohn's disease associated adherentinvasive $E$. coli bacteria target mouse and human Peyer's patches via long polar fimbriae. J. Clin. Invest. 121(3):966-975.

Chopra, A.K.; Huang, J.H; Xua, X.J.; Burdena, K.; Niesela, D.W.; Rosenbaum, M.W.; Popov, V.L. and Peterson, J.W. (1999): Role of Salmonella enterotoxin in overall virulence of the organism. Microb. Patho. 27(3):155-71.

Clermont, O.; Olier, M.; Hoede, C.; Diancourt, L.; Brisse, S. and Keroudean, M. (2011): Animal and human pathogenic Escherichia coli strains share common genetic back grounds. Infect. Genet. Evol., 11: 654-621.

Clinical and Laboratory Standards Institute "CLSI" (2013): Performance standards for antimicrobial susceptibility testing; twenty third informational supplements. M100-S23: $1-61$.

Coburn, B.; Grassl, G.A. and Finlay, B.B. (2007): Salmonella, the host and disease: a brief review. Immunol. Cell Biol. 85: 112-118.

Colom, K.; Pèrez, J.; Alonso, R.; FernándezAranguizA, LariňoE and Cisterna R. (2003): Simple and reliable multiplex PCR assay for detection of $b l a_{\mathrm{TEM}}, b l a_{\mathrm{SHV}}$ and $b l a_{\mathrm{OXA}-1}$ genes in Enterobacteriaceae. FEMS Microbiology Letters 223: 147-151.

El-Gedawy, A.A.; Ahmed, H.A. and Awadallah, M.A.I. (2014): Occurrence and molecular characterization of some zoonotic bacteria in bovine milk, milking equipments and humans in dairy farms, Sharkia, Egypt. International Food Research Journal 21(5): 1813-1823.

Fàbrega, A.; Madurga, S.; Giralt, E. and Vila, J. (2009): Mechanism of action of and resistance to quinolones. Microbial Biotechnology 2: 40-61.

Farrokh, C.; Jordan, K.; Auvray, F.; Glass, K.; Oppegaard, H.; Raynaud, S.; Thevenot, D.; Condron, R.; De Reu, K.; Govaris, A.; Heggum K.; Heyndrickx, M.; Hummerjohann, J.; Lindsay, D.; Miszczycha, S.; Moussiegt, S.; Verstraete, $K$. and Cerf, $O$. (2013): Review of Shiga-toxin-producing Escherichia coli (STEC) and their significance in dairy production. Int. J. Food Microbiol., 162:190-212.

FDA's Bacteriological Analytical Manual "BAM" (2017): Enumeration of Escherichia coli and the Coliform Bacteria. Chapter 4. 
Fernandes, J.B.C.; Zanardo, L.G.; Galvão, N.N.; Carvalho, I.A.; Nero, L.A. and Moreira, M.A.S. (2011): Escherichia coli from clinical mastitis: serotypes and virulence factors. Journal of Veterinary Diagnostic Investigation 23(6) $1146-1152$.

Foley, S.L.; Lynne, A.M. and Nayak, R. (2008): Salmonella prevalence in swine and poultry and potential pathogenicity of such isolates. J. Anim. Sci. 86 (Suppl): E149-62.

Galan, J.E. and Curtis, III R. (1989): Cloning and molecular characterization of genes whose products allow Salmonella Typhimurium to penetrate tissues culture cells. Pro. Natl. Acad, Sci. USA, 86:6383-6387.

Ghanbarpour, $R$. and Salehi, $M$ (2010): Determination of Adhesin Encoding Genes in Escherichia coli Isolates from Omphalitis of Chicks. American Journal of Animal and Veterinary Sciences 5 (2): 91-96.

Godinho, R.F. and Carvalho, R.C.R. (2013): Gestäo de sistemas de produçäo de leite. Ciência et Praxis, 2(3), 77-82.

Grasso, G.M.; Sammarco, M.L.; Ripabelli, G. and Fanelli, I. (2000): Enumeration of Escherichia coli and coliforms in surface water by multiple tube fermentation and membrane filter methods. Microbios., 103(405): 119-125.

Grimont, P.A.D. and Weill, F.X. (2007): Antigenic formulas of the salmonella serovars. $9^{\text {th }}$ ed. World Health Organization, Collaborating Centre for Reference and Research on Salmonella, Paris, France.

Guan, T.Y. and Holley, R.A. (2003): Pathogen survival in swine manure environments and transmission of human enteric illness: A review [Review]. J. Environ. Qual.32:383392.

Halimi, H.A.; Seifi, H.A. andRad, M. (2014): Bovine salmonellosis in Northeast of Iran: Frequency, genetic fingerprinting and antimicrobial resistance patterns of Salmonella spp. Asian Pac. J. Trop. Biomed., 4(1): 1-7.

Hayes, M.C.; Ralyea, R.D.; Murphy, S.C. and Carey, N.R. (2001): Identification and characterization of elevated microbial counts in bulk tank raw milk. Journal Dairy Science, 84:292-298.

Heithoff, D.M.; Conner, C.P.; Hanna, P.C.; Julio, S.M.; Hentsschel, $V$. and Mahan, M.J. (1997): Bacterial infection as assessed by in vivo gene expression. Proc. Natl. Acad. Sci. USA, 94: 934-939.

Hernandes, R.T.; Elias, W.P.; Vieira, M.A.M. and Gomes, T.A.T. (2009): An overview of atypical enteropathogenic Escherichia coli. FEMS Microbiol. Lett. 292: 137-149.

Hinthong, W.; Pumipuntu, N.; Santajit, S.; Kulpeanprasit, $\quad$ S.; Buranasinsup, $\quad$ S.;
Sookrung, N.; Chaicumpa, W.; Aiumurai, P. and Indrawattana, N. (2017): Detection and drug resistance profile of Escherichia coli from subclinical mastitis cows and water supply in dairy farms in Saraburi Province, Thailand. Peer J. 3431.

Hitchins, A.D.; Feng, P.; Watkins, W.D.; Rippey, S.R. and Chandler, L.A. (2001): E. coli and the coliform bacteria. In Bacteriological Analytical Manual, Chapter 4, $8^{\text {th }}$ edn, Revision A. Gaithersburg, MD: U.S. Food and Drug Administration, AOAC International.

Hu, Q.; Tu, J.; Han, X.; Zhu, Y.; Ding, C. and Yu, S. (2011): Development of multiplex PCR assay for rapid detection of Riemerellaanatipestifer, Escherichia coli, and Salmonella enterica simultaneously from ducks. Journal of Microbiological Methods, 87: 64-69.

Huang, W.M. (1996): Bacterial diversity based on type II DNA topoisomerase genes. Annu. Rev. Genet.30:79-107.

Huehn, S.; La Ragione, R.M.; Anjum, M.; Saunders, M.; Woodward, M.J.; Bunge, C.; Helmuth, R.; Hauser, E.; Guerra, B.; Beutlich, J.; Brisabois, A.; Peters, T.; Svensson, L.; Madajczak, G.; Litrup, E.; Imre, A.; HerreraLeon, S.; Mevius, D.; Newell, D.G. and Malorny, B. (2010): Virulotyping and antimicrobial resistance typing of Salmonella enterica serovars relevant to human health in Europe. Foodborne Pathogens Dis., 7: 52335.

Hussein, M.A.; Eldaly, E.A.; Seadawy, H.G. and ElNagar, E.F. (2008): Virulence and antimicrobial resistance genes of Escherichia coli in ready to eat sandwiches in Sharkia governorate. Slov. Vet. Res., 55 (Suppl 20): 383-392.

International Organization for Standardization "ISO 6579-1" (2017): Microbiology of the food chain -Horizontal method for the detection, enumeration and serotyping of -Part 1: Detection of Salmonella spp. (ISO 65791:2017).

International Organization for Standardization "ISO" (2017): Microbiology of the food chain -- Preparation of test samples, initial suspension and decimal dilutions for microbiological examination - Part 1: General rules for the preparation of the initial suspension and decimal dilutions. ISO, 6887-1.

International Organization for Standardization "ISO" (2017): Microbiology of the food chain -- Preparation of test samples, initial suspension and decimal dilutions for microbiological examination -- Part 4: Specific rules for the preparation of miscellaneous products. ISO, 6887-4.

International Organization for Standardization "ISO" (2017): Microbiology of the food 
chain -- Preparation of test samples, initial suspension and decimal dilutions for microbiological examination -- Part 5: Specific rules for the preparation of milk and milk products. ISO, 6887-5.

Jamshidi, A.; Bassami, M.R. and Afshari-Nic, S. (2008): Identification of Salmonella serovars Typhimurium by a multiplex PCR-Based assay from Poultry carcasses in MashhadIran. Int. J. Vet. Res., 3(1): 43-48.

Josland, S.W. (1951): Survival of Salmonella Typhimurium on various substances under natural conditions. Aust. Vet. J., 27:264-266.

Kaipainen, T.; Pohjanvirta, T.; Shpigel, N.Y.; Shwimmer, A.; Pyörälä, S. and Pelkonen, S. (2002): Virulence factors of $E$. coli isolated from bovine clinical mastitis. Vet. Microbiol., 26;85(1): 37-46.

Kaper, J.B.; Nataro, J.P. and Molby, H.L. (2004): Pathogenic Escherichia coli. Nat. Rev. Microbiol., 2: 123-140.

Karns, J.S.; Van Kessel, J.S.; McCluskey, B.J. and Perdue, M.I. (2005): Prevalence of Salmonella eneterica in bulk tank milk from US dairies as determined by polymerase chain reaction. J. Dairy, Sci, 88:2475-3479.

Kong, R.Y.C.; Dung, W.F.; Vrijmoed, L.L.P. and Wu, R.S.S. (1995): Co-detection of three species of water borne bacteria by multiplex PCR. Marine Pollution Bulletin, 31(4-12): 317-324.

Kong, R.Y.C.; So, C.L.; Law, W.F. and Wu, R.S.S. (1999): A sensitive and versatile multiplex PCR system for the rapid detection of enterotoxigenic (ETEC) enterohemorrhagic (EHEC) and enteropathogenic (EPEC) strains of Escherichia coli. Marine Pollution Bulletin, 38 (12): 1207 - 1215.

Lanz, R.; Kuhnert, P. and Boerlin, P. (2003): Antimicrobial resistance and resistance genes determinats in clinical Escherichia coli from different animals species in Swizerland. Vet. Microbiol., 91, 73-84.

Lee, M.D.; Curtiss, R.I. and Peay, T. (1996): The effect of bacterial structure on pathogenisi of salmonella Typhimurium infection in chickens. Avian Dis., 40:28-36.

Lietzau, S.; Raum, E.; Von Baum, H.; Marre, R. and Brenner, H. (2006): Clustering of antibiotic resistance of $E$. coli in couples: Suggestion for a major role of conjugal transmission. BMC Infect. Dis., 6: 1.

Lynne, A.M.; Rhodes-Clark, B.S.; Bliven, K.; Zhao, S. and Foley, S.L. (2008): Antimicrobial resistance genes associated with Salmonella enterica Serovar Newport isolates from food animals. Antimicrobial Agents and Chemotherapy, 52(1): 353-356.

Madsen, J.S.; Burmфlle, M.; Hansen, L.H. and Sorensen, S.J. (2012): The interconnection between biofilm formation and horizontal gene transfer. FEMS Immunol. Med. Microbiol., 65:183-195.

Mahmoud, A.K.; Khadr, A.M.; Elshemy, T.M.; Hamoda, H.A. and Ismail, M.I. (2015): Some Studies on $E$. coli Mastitis in Cattle and Buffaloes. Alexandria Journal of Veterinary Sciences, 45: 105-112.

Maity, T.K.; Kumar, R. and Misra, A.K. (2010): Prevalence of Enteropathogenic Escherichia coli Isolated from Chhana Based Indian Sweets in Relation to Public Health. Indian J. Microbiol., 50 (4): 463-467.

Malorny, B.; Hoorfar, J.; Bunge, C. and Helmuth, R. (2003): Multicenter Validation of the Analytical Accuracy of Salmonella PCR: towards an International Standard. Appl. Environ. Microbiol., 69(1): 290-296.

Maysa, A.I.A. and Abd-Elall, A.M.M. (2015): Diversity and virulence associated genes of Salmonella enterica serovars isolated from waste water agricultural drains, leafy green producing farms, cattle and human along their courses. Revue. Méd. Vét., 166(3-4):96106.

Mohamed, O.N.; Farid, A.F.; Abaza, A.F. and Faltas, R.F. (2011): Fecal Shedding of Nontyphoidal Salmonella Species in Dairy Cattle and their Attendants in Alexandria Suburbs. Journal of American Science, 7(9):623-631

Mohler, V.L. and House, J. (2009): Salmonellosis in ruminants. In: Anderson D. E., Rings D. M., editions. Current veterinary therapy- Food animal practice. $5^{\text {th }}$ ed. St. Louise, Mi: Saunders Elseviere :106-111.

Moll, A.; Manning, P.A. and Timmis, K.N. (1980): Plasmid- determined resistance to serum bactericidal activity: a major outer membrane protein, the traT gene product, is responsible for plasmid-specified serum resistance in Escherichia coli. Infection and Immunity, 28: 359-367.

Murugkar, H.V.; Rahman, H. and Dutta, P.K. (2003): Distribution of virulence genes in Salmonella serovars isolated from man and animals. Indian J. Med. Res., 117: 66-70.

Nakamura, S.; Nakamura, M.; Kojima, T. and Yoshida, H. (1989): gyrA and gyrB mutations in quinolone-resistant strains of Escherichia coli. Anti-microb Agents Chemother., 33(2) :254-255.

Nastasi, A.; Mammina, C. and Villafrate, M.R. (1993): Epidemiology of Salmonella Typhimurium: ribosomal DNA analysis of strains from human and animal sources. Epidemiol. Inject., 110: 553-565.

Nemeth, J.; Muckle, C.A. and LO, R.Y.C. (1991): Serum resistance and the traT gene in bovine mastitis-causing Escherichia coli. Veterinary Microbiology, 28: 343-351.

Nguyen, M.C.P.; Woerther, P.; Bouvet, M.; Andremont, A.; Leclercq, R. and Canu, A. 
(2009): Escherichia coli as reservoir for macrolide resistance genes. Emerging infectious diseases, 15 (10).

Olivera, S.D.; Rodenbusch, C.R.; Ce, M.C.; Rocha, S.L.S. and Canal, C.W. (2003): Evaluation of selective and non-selective enrichment PCR procedures for Salmonella detection. Lett. Appl. Microbiol., 36: 217-221.

Ørskov, F. and Ørskov, I. (1984): Serotyping of Escherichia coli. Methods in microbiology Vl. 14, Collaborative Centre for Reference and Research on Escherichia and Klebsiella, (WHO), Statens Seruminstitut, Copenhagen, Denmark.

Pai, H.; Kang, C.I.; Byeon, J.H.; Lee, K.D.; Park, W.B. and Kim, H.B. (2004): Epidemiology and clinical features of bloodstream infections caused by $a m p C$ type-betalactamase-producing Klebsiella pneumoniae. Antimicrob. Agents Chemother.; 48(10): 3720-8.

Pamela, L.; Rinemann, D. and Kathryn H. (2008): The effect of milking management on microbial quality presented at XII curso Novas Enfoques Na producase reproduced de Bovinos, Uberlandia, Brazil March 6-8.

Phillips, I.; Mark, C.; Cox, T.; Groot, B.D.; Christian, F.; Jones, R.; Charles, N.; Rodney, $P$. and John, W. (2004): Does the use of antibiotics in food animals pose a risk to human health? A critical review of published data. Journal of Antimicrobial Chemotherapy 53: 28-52.

Public Health Agency of Canada (2007): Salmonella Heidelberg-ceftiofur-related resistance in human and retail chicken isolates. Public Health Agency of Canada, Guelph, Ontario, Canada.

Randall, L.P.; Cooles, S.W.; Osborn, M.K.; Piddock, L.J.V. and Woodward, M.J. (2004): Antibiotic resistance genes, integrons and multiple antibiotic resistance in thirty-five serotypes of Salmonella enterica isolated from humans and animals in the UK. Journal of Antimicrobial Chemotherapy, 53: 208216.

Rotger, R. and Casadesus, J. (1999): The virulence plasmids of Salmonella. Int. Microbiol., 2: 177-184.

Rúgeles, L.C.; Bai, J.; Martinez, A.J.; Vaneges, M.C. and Gomez-Duarte, O.G. (2010): Molecular characterization of diarrheagenic Escherichia coli strains from stools samples and food products in Colombia, International Journal of Food Microbiology, 138(3): 282286.

Sawant, A.A.; Hegde, N.V; Straley, B.A.; Donaldson, S.C.; Love, B.C.; Knabel, S.J. and Jayarao, B.M. (2007): Antimicrobial resistant enteric bacteria from dairy cattle. Appl. Environ. Microbiol., 73: 156-163.
Sayed, S.M. (2014): A contribution on Coliforms causing mastitis in cows with reference to serotypes and virulence factors of $E$. coli isolates. Assiut University Bulletin for Environmental Researches 17 (1):85-95.

Solomakos, N.; Govaris, A.; Angelidis, A.S.; Pournaras, S.; Burriel, A.R.; Kritas, S.K. and Papageorgiou, D.K., (2009): Occurrence, virulence genes and antibiotic resistance of Escherichia coli $\mathrm{O} 157$ isolated from raw bovine, caprine and ovine milk in Greece. Food Microbiol., 26: 865-871.

Sotohy, S.S. and Khalifa, E. (2018): Molecular characterization of some virulence genes of Salmonella enterica serotype Sandow and Saintpaul isolated from environment of dairy farms at Assiut Province, Egypt. J. Vet. Sci Technical., 9 (5): 1-5.

Srinivasan, $\quad$ V.; Nam, H.M.; Nguyen, L.T.; Tamilselvam, B.; Murinda, S.E. And Oliver, S.P. (2005): Prevalence of Antimicrobial Resistance Genes In Listeria monocytogenes isolated From Dairy Farms. Food-borne Pathogens and Disease, 2 (3).

Suojala, L.; Pohjanvirta, T. and Simojokietal, H. (2011): Phylogeny, virulence factors and antimicrobial susceptibility of Escherichia coli isolated in clinical bovine mastitis. Veterinary Microbiology, 147(3-4):383-388.

Tamba, Z.; Bello, M. and Raji, M.A. (2016): Occurrence and antibiogram of salmonella spp. in raw and fermented milk in zaria and environs. Bangl. J. Vet. Med., 14 (1): 103107

Tamura, K.; Stecher, G.; Peterson, D.; Filipski, A. and Kumar, S. (2013): MEGA6: molecular evolutionary genetics analysis version 6.0. Mol. Biol. Evol., 30: 2725-2729.

Thompson, J.D.; Higgins, D.G. and Gibson, T.J. (1994): Clustal w: improving the sensitivity of progressive multiple sequence alignment through sequence weighting, position-specific gap penalties and weight matrix choice. Nucleic Acids Research, 22(22): 4673-4680.

Van Kessel, J.A.S.; Karns, J.S.; Lombard, J.E. and Kopral, C.A. (2011): Prevalence of Salmonella enterica, Listeria monocytogenes, and Escherichia coli virulence factors in bulk tank milk and in-line filters from US dairies. J. Food. Prot. 74:759-768.

Wang, J.; Li, Y.; Xu, X.; Liang, B.; Wu., F.; Yang, X.; Ma, Q.; Yang, C.; Hu, X.; Liu, H.; Li, H.; Sheng, C.; Xie, J.; Du, X.; Hao, R.; Qiu, S. and Song, H. (2017): Antimicrobial Resistance of Salmonella enterica Serovar Typhimurium in Shanghai, China. Frontiers in Microbiology, 8, Article 510.

Warnick, L.D.; Kaneene, J.B.; Ruegg, P.I.; Wells, S.J.; Fossler, C. and Hallert, I. (2003): Evaluation of herd sampling for Salmonella 
isolation on Midwest and northeast US dairy farms. Prev. Vet. Med, 60: 195-206.

Wassef, M.; Behiry, I.; Younan, M.; El Guindy, N.; Mostafa, S. and Abada, E. (2014): Genotypic identification of $A m p C \quad \beta$-Lactamases production in Gram negative Bacilli Isolates. Jundishapur J. Microbiol;; 7(1): e8556, 1-8.

Wells, S.J.; Fedorka-Cray, P.J.; Dargatz, D.A.; Ferris, K. and Green, A. (2001): Fecal Shedding of Salmonella spp. by Dairy Cows on Farm and at Cull Cow Markets. Journal of Food Protection, 64 (1): 3-11.

World Health Organization/Food and Agriculture Organization of the United Nations (WHO/FAO) (1994): Basic Procedures for Veterinary Laboratories in Developing Countries, Pini A., Parodi P., Demeneghi D., Belemu U., Kabilika H. \& Ghirotti M., eds. WHO/FAO Collaborating Centre, Viale Regina Elena 299, 00161 Rome, Italy, pp. 142.

World Health Organization "WHO" (1987): Program for control of diarrheal diseases (CDD/83.3 Rev. 1). Manual for laboratory investigations of acute enteric infections, Geneva.

Yassin, A.K.; Gong, J.; Kelly, P.; Lu, G.; Guardabassi, L.; Wei, L.; Han, X.; Qiu, H.; Price, S. and Cheng, D. (2017): Antimicrobial resistance in clinical Escherichia coli isolates from poultry and livestock, China. PLOS One, 12(9):1-8.

Yoshida, H.; Kojima, T.; Yamagishi, J. and Nakamura, S. (1988): Quinolone-resistant mutations of the gyrA gene of Escherichia coli. Mol. Gen. Genet. 211: 1-7.

$Y$ u, K.X. and Thong, K.L. (2009): Multiplex PCR for Simultaneous Detection of Virulence Genes in Escherichia coli. Malaysian Journal of Science 28 (1): 1-14.

Zhao, S.; White, D.G.; Friedman, S.L. Glenn, A.; Blickenstaff, K.; Ayers, S.L.; Abbott, J.W.; Hall-Robinson, E. and McDermott, P.F. (2008): Antimicrobial Resistance in Salmonella enterica Serovar Heidelberg isolates from Retail Meats, Including Poultry, from 2002 to 2006. Applied and Environmental Microbiology, 74, (21): 66566662.

\title{
الكشف الجزيئي عن ميكروبات السالمونيلا والاشرشيا كولاي في مزارع الالبان مع الكثف عن جينات الضراوة

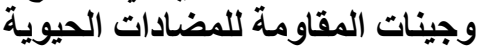

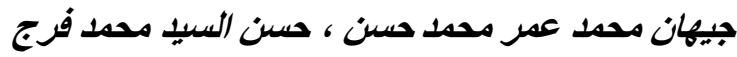

E-mail: dr.gehanomer@yahoo.com Assiut University web-site: www.aun.edu.eg

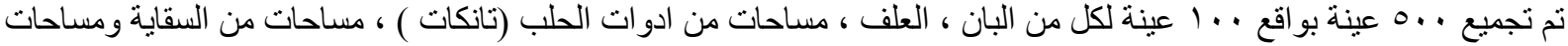

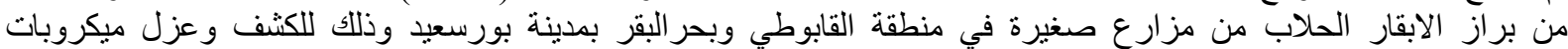

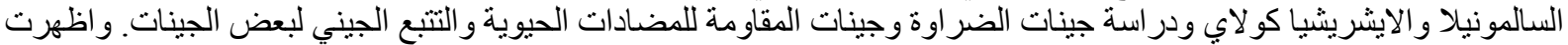

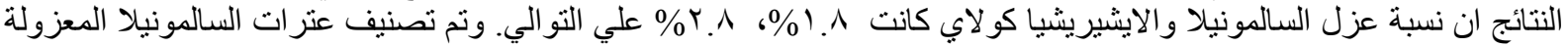

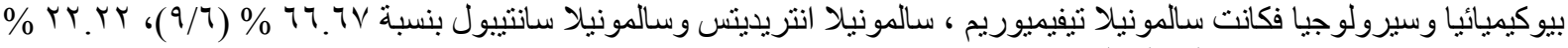

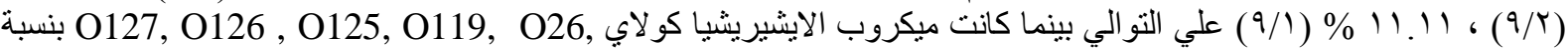

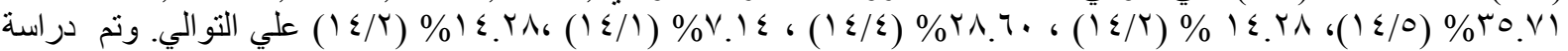

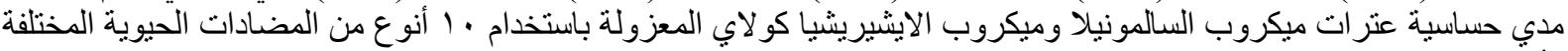

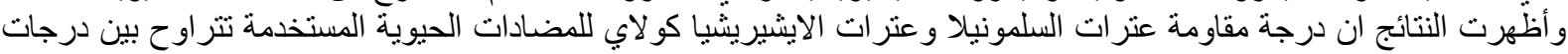

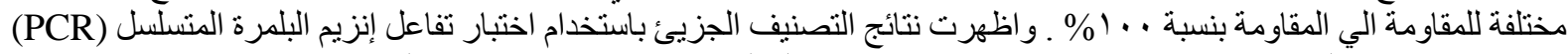

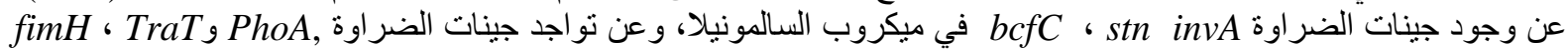
لميكروب الايشيريشيا كولاي. وعن إن لميكروبات السالمونيلا وجينات المقاومة aacC, Aadal, mphA, ،blaTEm,, ampC

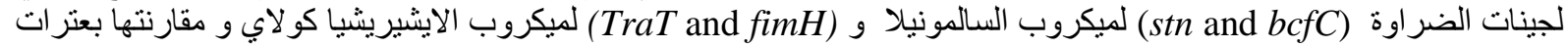

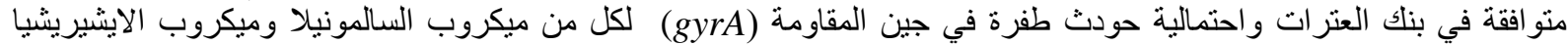

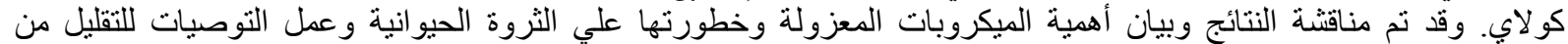
مخاطر ها في مز ارع الألبان.
\end{abstract}

